\title{
A TECHNOLOGY PORTFOLIO OPTIMIZATION MODEL CONSIDERING STAGED FINANCING AND MORATORIUM PERIOD UNDER UNCERTAINTY
}

\author{
Marzieh Shaverdi ${ }^{1}$ AND SaeEd Yaghoubi ${ }^{2, *}$
}

\begin{abstract}
Technology commercialization needs a large amount of financial resources and governments in developed and developing countries play a critical role in resource allocation to the technology commercialization, especially through "Technology Development Funds (TDFs)". But, because of resource limitations, determining high priority technologies with higher impact on the country's innovative performance and the optimal resource allocation to technology development is very important for science and technology policymakers. "Technology portfolio planning" has been developed and applied in this regard. Accordingly, a two-phase decision-making framework has been proposed. At the first phase, the priorities of technology fields are determined by using the best-worst method (BWM) and at the second phase, a two-stage stochastic technology portfolio planning model is developed by considering technological projects' risks and export market, as one of the important factor in the "Global Innovation Index" (GII) ranking. It also has been considered technology fields' priorities, staged-financing, moratorium period, reinvestment strategy, and technology readiness levels (TRL) in allocating financial resources to technological projects The main advantages of our proposed model are considering uncertainty and early signaling about under performing technological projects Due to the uncertain nature of the problem, our solution methodology is based on the Sample Average Approximation (SAA). In order to demonstrate the applicability of this model, a real case study and its computational results are presented.
\end{abstract}

Mathematics Subject Classification. 90B50, 90C90.

Received June 30, 2019. Accepted April 4, 2020.

\section{INTRODUCTION}

Managing the innovation and technology development is mostly accomplished in a coherent and integrated system, called "National Innovation System" (NIS). NIS is the system of institutions, private and public firms, universities and government agencies that aims at the production, diffusion and exploitation of knowledge within the national borders of countries [49]. "Innovation Financing System" (IFS) is one of the subsystems of NIS which has the responsibility of financing technology development. Technology financing could be defined as the process of funding innovative businesses to turn their technological inventions into commercial innovative

Keywords. Technology portfolio optimization, Staged financing, Moratorium period, Stochastic model, Sample average approximation (SAA).

1 School of Progress Engineering, Iran University of Science and Technology, Tehran, Iran.

2 School of Industrial Engineering, Iran University of Science and Technology, Tehran, Iran.

*Corresponding author: yaghoubi@iust.ac.ir 
products or services [50]. Prioritizing technologies and financing the innovative firms' technological activities is a challenging issue which governments usually face with. Technology financing has a crucial role in supporting high-technology firms at different stages of the innovation process. At the first stage of firms' life cycle, the investment is associated with a high risk of failure, and private investors are unwilling to finance firms' activities, so, start-up firms often face difficulties in access to financial resources from banks or other financial institutions [48]. At the next stages, with the growth of a company financially, other investors, including governmental "Technology Development Funds" (TDFs) and private investors, may provide financial resources for such firms [50]. Governments have made attempts to design a diverse range of financial support in accordance with the needs of these developing firms [17]. Finally, when firms become mature, they may have the opportunity of using IPO and stock market to finance their activities [50].

Because of the importance of technological innovation and "knowledge-based economy", some studies have explored the concept of the technology financing and commercialization systems in different countries $[6,48,50]$. Such studies have depicted the big picture of innovation financing policies, IFS of countries, their institutions, and the role of them in each phase of technology development. However, there are limited studies exploring quantitative methods for technology prioritizing and resource allocation in TDFs, motivating this study to revolve around the role of TDFs in IFS, as organizations that finance the countries' innovation and technology development.

TDFs are governmental financial institutions which have the responsibility of supporting technology development at the national level. Since the financial resources are limited, the TDFs should have a prioritization mechanism to optimize the allocation of resources to different technology fields and technological projects in each field. But, so far no technology portfolio optimization model has been developed for TDFs and resource allocation almost done by qualitative assessment and based on experts' judgment.

With regard to these considerations, and also by bearing in mind that different technologies have different effects on the knowledge-based economy, high-tech export potential, and country's overall position at innovation and competitiveness rankings, optimal resource allocation can improve the effectiveness and efficiency of the TDFs' financial resources significantly. Hence, in this paper, a two-phase framework for TDFs' technology portfolio planning is developed which makes it possible to determine the optimal technology portfolio composition and to allocate resources to different technological projects based on the periodical assessment. In the first phase of this framework the priority of different technology fields is determined and in the second phase resource allocation to different technological project is done by using a two-stage stochastic technology portfolio planning model that considers technology fields' priorities (from the first phase), export market, return on investment of technological projects, technology readiness level (TRL), and technical progress of projects.

The main contributions of this study that differentiates it from others are as follows:

- Developing a two-phase framework for decision-making about resources allocation to technological projects.

- Proposing a two-stage stochastic model combining BWM and SAA methods for technology portfolio planning.

- Considering two levels for technology portfolio planning: "technology fields" and "technological projects in each technology field".

- Presenting a model by taking into account the important technological factors such as technology readiness level (TRL), technology leverage factor (TLF), and the potential export market for portfolio optimization.

- Considering periodical assessment of technological projects and staged financing of them according to their technical progress.

- Considering interdependency and inconsistency between different technological projects.

- Taking into consideration the moratorium period for loans repayment.

- Demonstrating the applicability of the proposed model through a real case study in Iran's Innovation and Prosperity Fund (IPF).

The remainder of the paper is organized as follows: In Section 2, the related literature review is presented. In Section 3, the proposed model for technology portfolio selection and staged financing of technological projects 
is formulated, and its solution approach is presented in Section 4. The practicality of the proposed model in the real case and managerial insights obtained from the computational results are presented in Section 5. Section 6 presents managerial insights, and concluding remarks and future research recommendations are presented in Section 7 .

\section{Literature REVIEW}

Portfolio selection has been one of the hottest topics in finance and stock markets for years. The original research in this field is the work of Markowitz [25] on proposing a mean-variance model for portfolio selection problem that has played an important role in the development of modern portfolio theory.

In recent years, with the increase in the importance of technology in countries' competitiveness, portfolio concepts entered into the management of technology literature, although there are limited works in this field. In this section, the most related literature in terms of "stock market portfolio", "project portfolio" and "technology portfolio" is reviewed. Portfolio management includes a wide range of tools and methods ranging from quantitative to qualitative. Noteworthy, this section mainly focuses on studies with the quantitative models, which are briefly shown in Table 1.

In the context of the stock market, Kocadağlı and Keskin [19] proposed a multi-objective fuzzy model of portfolio selection that takes into consideration the risk priorities according to market trends as well as the risk-return tradeoff, which enables decision makers to determine importance and priority of designated goals. Kucukbay and Araz [20] have presented a linear physical programming (LPP) model to determine the optimal portfolio composition, considering two criteria of expected return and risk. They also have compared the portfolio selected by applying LPP with the combination of portfolio gained from fuzzy goal programming (FGP) and have found that LPP can be considered a good alternative for FGP method. Huang et al. [15] developed a multiobjective decision-making model for portfolio selection at the stock market of Taiwan. They combined DEA with an MODM model. Their proposed methodology includes three stages: stock screening, portfolio selection with DEA method, and resource allocation. Mashayekhi and Omrani [27] proposed a multi-objective model for portfolio selection at the stock exchange market. Their model combines DEA with Markovitz mean-variance model by incorporating the risk, return, and efficiency of each portfolio into the modelling.

In addition to considering uncertainty, some models have considered multi-period of portfolio planning. In order for dealing with the stock markets uncertainty and planning for multiple periods, Mohebbi and Najafi [29] developed a bi-objective mean-VaR portfolio selection model through the integration of fuzzy credibility theory and scenario tree. They have considered liquidity, cardinality, investment threshold, and different industries in their model. Their solution algorithm is based on interactive multi-objective dynamic programming. Li et al. [22] presented a multi-period model for stock market portfolio selection under uncertainty. This is a threestage model that aims at maximizing the final wealth of the investor and minimizing the risk of investment. Factors such as transaction costs, bankruptcy, and cardinality are considered as the model's constraints.

Because of the increasing role of innovation and technology in economies and on the other hand because of the limited availability of financial resources, a variety of tools and methods have been developed to prioritize technologies and select the optimal set of innovative projects and allocate financial resources to them. In order to optimize a portfolio of product development improvement projects, Dickinson et al. [7] by using a dependency matrix, presented a nonlinear, integer programming model for the Boeing Company. This model considers the interdependencies between projects and is about to balance the risk, cost, and benefit of the entire portfolio.

The difficulty of selecting a portfolio is mainly due to the multiple conflicting objectives, inherent technical complexity, and uncertainties in the decision-making process. Litvinchev et al. [23] presented a nonlinear discontinuous bicriterion optimization model for R\&D portfolio selection in social institutions, state-owned enterprises, and other nonprofit organizations. Tavana et al. [43] also proposed a data envelopment analysis (DEA) model addressing the ambiguity and vagueness of parameters. Their multi-objective fuzzy linear programming model has been developed for assessing high-tech projects in the National Aeronautics and Space Administration (NASA). The proposed model combines different decision-makers opinions about fuzzy inputs 


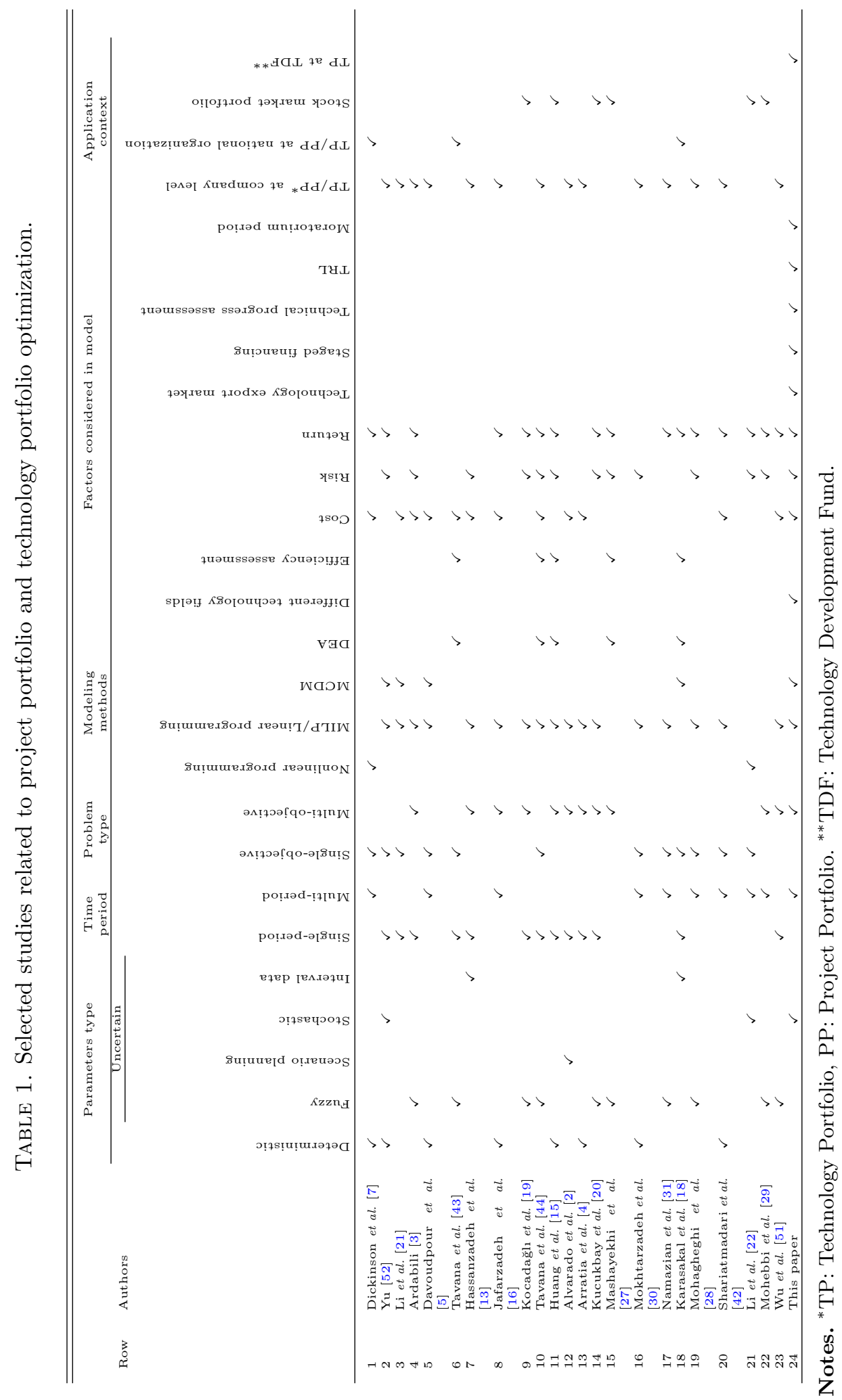


and outputs. They used the $\alpha$-level based approach for their fuzzy DEA model. Hassanzadeh [13] proposed a multi-objective model for $R \& D$ projects portfolio selection in uncertainty conditions. They have used robust optimization in order to solve the problem and also have applied an interactive procedure for a tradeoff among multiple objectives of the model.

Tavana et al. [44] considered projects portfolio matching with the organization's goal and mission and proposed a three stages model for projects portfolio selection. They used DEA for primary projects screening, TOPSIS for projects ranking, and linear-integer programming for selecting the most appropriate projects portfolio in a fuzzy environment.

Determining the projects scheduling and their sequence are important issues that some portfolio optimization models take into consideration. Jafarzadeh et al. [16] have considered the fact that projects have different durations and potential rates of return, and the profit yielded by the implemented projects could be reinvested in the other projects. With these assumptions in mind, they have used re-investment strategy within a flexible time horizon and have proposed a model for optimal project portfolio selection. They consider a three-objective integer programming to determine project composition, schedule the selected projects, and determine their time horizon. Namazian and Haji Yakhchali [31] have proposed a fuzzy model for portfolio selection, scheduling the projects' execution sequence and appropriate contractor selection for each activity. This model aims at executing projects in the shortest timeframe and considers profitability and execution time of the activities as constraints. Shariatmadari et al. [42] have presented a mixed-integer programming (MIP) model for simultaneous project selection and scheduling. This model is about to maximize available cash at the end of the planning horizon and takes into account the precedence relations in each project, resource availability and completion of selected projects in the planning horizon as constraints. As the solution method, first a heuristic algorithm is developed to generate feasible initial solutions; then based on Gravitational Search Algorithm a method is developed for improving the resulted solutions.

Interdependency and the synergy among projects is an important factor in portfolio selection. So, Arratia et al. [4] proposed a multi-objective mathematical model to select $\mathrm{R} \& \mathrm{D}$ projects at a public organization that takes into consideration interdependencies and synergies among projects and activities. In their framework, each project proposal includes tasks with different types of costs. Mokhtarzadeh et al. [30] have developed a three-dimensional model for $\mathrm{R} \& \mathrm{D}$ projects portfolio selection which considers three criteria including the risk, attractiveness, and competitiveness. Additionally, their model considers the interdependencies among different projects in the form of a multi-objective framework with deterministic variables. Mohagheghi et al. [28] have proposed a new interval type-2 fuzzy optimization approach for R\&D projects portfolio selection. This model considers risk and return simultaneously as the objective function, and takes into account the constraints of budget, human resources, interdependency and inconsistency among projects. Wu et al. [51] have developed a multi-stage framework for photovoltaic projects' portfolio selection under uncertainty. In the first stage, by using the PROMETHEE II method undesirable options are eliminated. Then, the portfolio is selected by means of a fuzzy zero-one programming model. This model is about to maximize benefit and installed capacity.

Karasakal and Aker [18] proposed two threshold estimation models and five assignment frameworks based on DEA approach to sort and rank the R\&D projects. They used a five-level hierarchical structure to define $R \& D$ project selection criteria. This structure has used for determining the importance of the criteria; and because the evaluation criteria include the inputs and outputs of the projects, they developed a DEA-based model to sort the projects.

Technological projects, as the key elements to keep firms competitive in today's world, need to be optimized by decision makers in order to bring about the most profit and lowest risk. Yu [52], in his book, entitled "Technology Portfolio Planning and Management", developed a linear single-period model under uncertainty conditions which incorporated the limit of the budget, employee's time, and managerial time in the model. By considering enterprise economic and environmental benefits and the synergies among different technologies, Li et al. [21] proposed a methodology to select a green technology portfolio. They used the AHP method to calculate the weights of enterprise benefits and the ANP method to assess the synergies among the different types of technologies. 
Ardabili [3], in order to consider vague data gathered from a real-world setting, developed a multi-objective, single-period model with random fuzzy technologies return to optimize a technology portfolio selection problem.

The increasing complexity of new technology development in the dynamic business environment has made the optimum technology selection more complicated. To successfully plan for investment in renewable energy projects, Davoudpour et al. [5] presented a mathematical model for renewable technology portfolio selection applied at an oil industry R\&D centre with the objective of maximizing technologies support of the organization's strategy and values. Their model tries to set an appropriate balance between the cost and benefit of the entire portfolio. Using AHP method, they first determined the importance of assessment criteria for renewable technology portfolio; and then, proposed a mathematical model with deterministic variables for portfolio selection.

Metrics such as Technology Readiness Level (TRL) are used to specify the maturity level of a given technology, thereby providing an evaluation criterion of the needed steps and funding requirements for technology commercialization. Terrile et al. [45] considered TRL as a proxy in order to reduce the risk of portfolio selection. They proposed other measures such as "Technology Leverage Factor" (TLF) and market size as a proxy for reward in technology portfolio selection at NASA. Their model is a qualitative framework for technology portfolio selection based on risk and reward matrix. Environmental considerations have become a very important factor in technology portfolio selection in recent years. Alvarado et al. [2] presented a mixed-integer linear model to optimize the technology portfolio selection and apply them in buildings' energy systems. This model regards whole life costs, carbon emissions, real-time energy prices, and demands. Although there are several papers addressing the portfolio selection problem, most identified references are dealing with "stock market portfolio" or "project portfolio" as well as "R\&D project portfolio"; as seen in Table 1.

A little work has been done in "technology portfolio optimization". Moreover, the vast majority of papers consider the portfolio concept at a company level while seeking to optimize the portfolio composition by considering risk, return, costs and synergies between different projects. None of the previous studies in technology portfolio optimization, consider technology readiness level (TRL), technical progress, and technology leverage factor (TLF), in their proposed quantitative models. Furthermore, staged-financing, moratorium period and reinvestment strategy are neglected issues in the previous works. In addition, the context in which the proposed models could be applied is company level, where important factors in global innovation rankings are not considered. By considering the enhancement of the country's position in the global rankings such as GII, and by gathering the Iran's science, technology and innovation (STI) experts opinion, the proposed framework tries to prioritize the technology fields based on the criteria such as infrastructure, human capital, knowledge \& technology outputs, etc. and then determine the optimum composition of technological projects and their financing method considering uncertainty and based on projects' risk, technological properties, technical progress and impact on developing export market.

\section{Proposed FrameWORK}

Our proposed framework has a two-phase framework that integrates BWM with a two-stage stochastic model. The schematic view of this framework is presented in Figure 1.

\subsection{Phase 1. Technology prioritizing}

This phase is composed of three stages:

\section{P1. Identify decision-makers (DMs)}

At this stage identification of DMs including senior managers or specific committee members in the field of science and technology policy, and innovation financing is done. 


\section{Phase 1. Technology Prioritizing (3.1)}

\section{P1. Identify Decision-Makers (DMs)}

P2. Identify criteria for technology fields' prioritizing (Figure 2)

P3. Calculate the priority number of technology fields using BWM

Phase 2. A two-stage stochastic portfolio planning model (3.2)

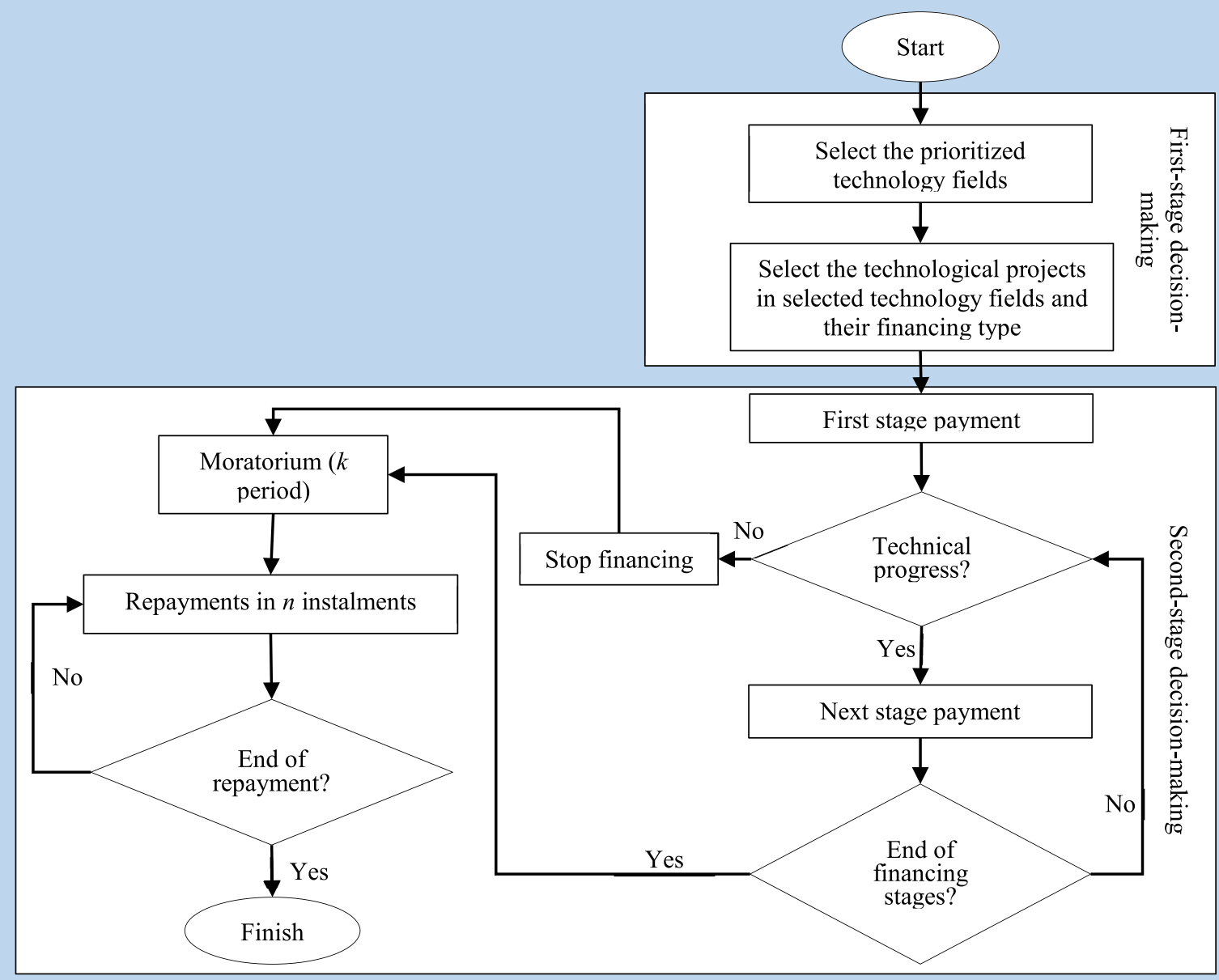

FiguRE 1. Proposed framework. 


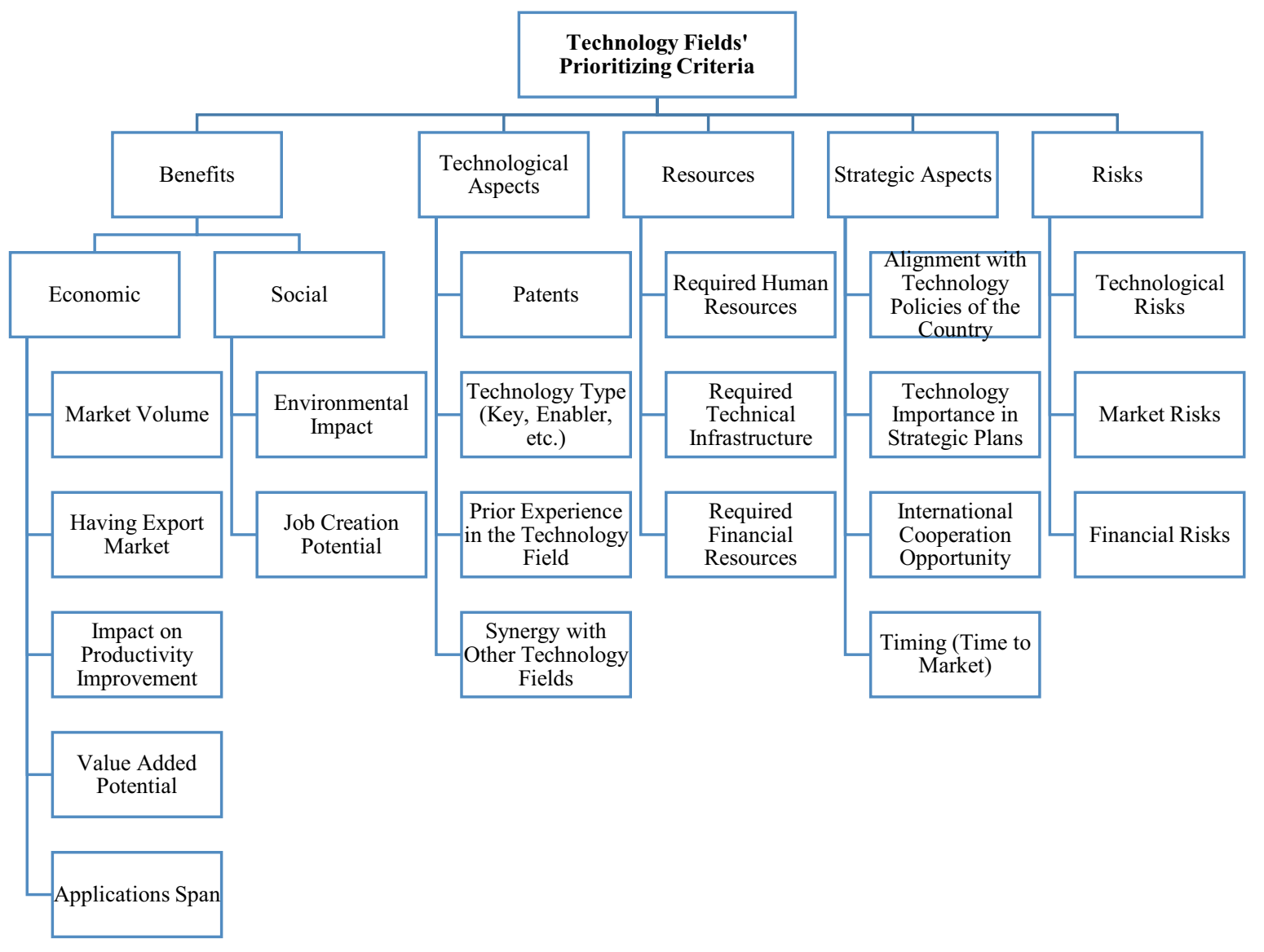

FiguRE 2. The criteria for technology fields' prioritizing.

\section{P2. Identify criteria for technology fields' prioritizing}

At the second stage, the important criteria in technology assessment and prioritizing were identified based on resources such as Karasakal and Aker [18], Davoudpour et al. [5], and Ghazinoori and Ghazinoori [9]. Then there were presented to the science and technology policy experts and based on their opinion, the final criteria categories and subcategories were developed (Fig. 2).

\section{P3. Calculate the priority number of technology fields using BWM}

There are several multi-criteria decision-making methods, such as AHP, TOPSIS, PROMETHEE, ELECTRE and SAW [47]. In our paper, a new method called Best Worst Method (BWM) was used that is introduced by Rezaei [34].

The BWM has been used as it is the novel method in MCDM, although it is based on pairwise comparisons, it requires fewer comparison data compared to the AHP and ANP and, also produces more reliable results. The total number of pairwise comparisons in BWM is $2 n-3$ but in AHP methods there should be done $\frac{n(n-1)}{2}$ pairwise comparisons [34]. In this regard, BWM makes the judgment easier, faster and more understandable for decision makers. This method has been successfully applied in different studies in various fields such as risk assessment [46], supplier segmentation [34], supplier selection [11,35], technological innovation assessment [10], Ph.D. efficiency assessment [39], Quality assessment of scientific outputs [38], and R\&D performance assessment 
[40]. But the BWM has not been used in the science and technology policy-making and determining technology priorities before.

The steps of BWM to calculate the weights for the main criteria and sub-criteria are as follows [34,35, 38]:

Step 1. Determine a set of criteria and sub-criteria. In this step, $n$ criteria $\left\{c_{1}, c_{2}, \ldots, c_{n}\right\}$ has been identified and used for decision making.

Step 2. Determine the best (e.g. most important) and the worst (e.g. least important) criterion according to the decision-makers' perspective.

Step 3. Determine the preference of the best criterion over all the other criteria, using a number between 1 and 9 ( 1 means $i$ is equally important to $j ; 9$ means $i$ is extremely more important than $j$ ). The result of this step is a Best-to-Others (BO) vector:

$$
A_{B}=\left(a_{B 1}, a_{B 2}, \ldots, a_{B n}\right)
$$

in which $a_{B j}$ indicates the preference of the best criterion $B$ over criterion $j$ and $a_{B B}=1$.

Step 4. Determine the preference of all the criteria over the worst criterion, using a number between 1 and 9 . The result of this step is Others-to-Worst (OW) vector:

$$
A_{W}=\left(a_{1 W}, a_{2 W}, \ldots, a_{n W}\right)^{T}
$$

in which $a_{j W}$ indicates the preference of the criterion $j$ over the worst criterion $W$ and $a_{W W}=1$.

Step 5. Find the optimal weights $\left(w_{1}^{*}, w_{2}^{*}, \ldots, w_{n}^{*}\right)$. So, we should find the solution that minimizes the absolute differences $\left|\frac{w_{B}}{w_{j}}-a_{B j}\right|$ and $\left|\frac{w_{j}}{w_{W}}-a_{j W}\right|$ for all $j$. In other words, the following minimax model should be solved:

$$
\begin{aligned}
& \underset{j}{\operatorname{Min} \max _{j}}\left\{\left|\frac{w_{B}}{w_{j}}-a_{B j}\right|,\left|\frac{w_{j}}{w_{W}}-a_{j W}\right|\right\} \\
& \text { s.t. } \\
& \qquad \sum_{j} w_{j}=1 \\
& \quad w_{j} \geq 0 \quad j=1,2, \ldots, n .
\end{aligned}
$$

This problem could be translated into the following linear problem:

$$
\begin{array}{ll}
\text { Min } \xi^{L} & \\
\text { s.t. } & \\
& \left|w_{B}-a_{B j} w_{j}\right| \leq \xi^{L} \quad j=1,2, \ldots, n \\
& \left|w_{j}-a_{j W} w_{W}\right| \leq \xi^{L} \quad j=1,2, \ldots, n \\
& \sum_{j} w_{j}=1 \\
& w_{j} \geq 0 \quad j=1,2, \ldots, n .
\end{array}
$$

By solving this problem, the optimal weights $\left(w_{1}^{*}, w_{2}^{*}, \ldots, w_{n}^{*}\right)$ (i.e. priority number of each technology field) and $\xi^{L *}$ are obtained. The $\xi^{L *}$ is considered as consistency index and the closed its value to zero, the higher the consistency level of comparisons.

To determine the priority number for each alternative, the score of alternatives with regard to each criterion should be determined. Then the weighted score for each criterion could be calculated by multiplying the score and the weight. The overall score is determined by the summation of the weighted scores. 


\subsection{Phase 2. A two-stage stochastic portfolio optimization model}

At this phase, a two-stage stochastic model for technology portfolio selection is presented.

Our proposed model determines the optimal composition of technology fields and technological projects in order to finance by TDFs. This model considers uncertainty (by considering different scenarios), different debt financing types (including loans with different interest rate, moratorium and repayment periods), moratorium period for loans, repayment and reinvestment strategy, and staged financing of technological projects with regard to their technical progress.

The following notations are used in problem mathematical modelling (Tab. 2).

In the presented model, there are two types of variables: The first-stage variables are independent of scenarios and decisions about them are made "here-and-now" prior to the realization of uncertainty. In this study, the selection of technology fields $\left(\gamma_{j t}\right)$, technological projects $\left(\sigma_{f j g}\right)$ and determining their financing stages $\left(\lambda_{f j g t}\right)$ are the first-stage variables. The minimum and maximum level of capital that could be allocated to TDFs are calculated as a percentage of the government budget which is associated with the oil price. Regarding the oil price fluctuations, the amount of capital allocation could not be determined exactly. Hence, the minimum and maximum level of capital has been considered as uncertain parameters. The probability distribution for uncertain parameters is considered to be a uniform distribution, so we will have different scenarios for these parameters. Second-stage variables, that are dependent to the uncertain parameters, are scenario-dependent and include the amount of financing in each stage $\left(X_{f j g t s}\right)$, allocated capital to the organization $\left(\mathrm{Ca}_{t s}\right)$, available budget $\left(C_{t s}\right)$ and allocated resources to each field $\left(B_{j t s}\right)$. The decision about these variables is postponed in a "wait-and-see" mode and they are determined after the uncertainty of the random parameters $\left(\operatorname{Camax}_{s}\right.$ and Camin $_{s}$ ) has been resolved.

In this section, a scenario-based two-stage stochastic optimization model is proposed to deal with the uncertainty in the problem. The two-stage stochastic optimization model could be written as follows:

$$
\begin{aligned}
& \operatorname{Max} Z=w_{1}\left(\operatorname{Max} Z_{1}\right)-w_{2} E\left[Z_{2}\right] \\
& \text { s.t. } \\
& \gamma_{j t} \times P_{\min } \leq P_{j t}, \quad j=1,2, \ldots, J, \quad t=1,2, \ldots, T \\
& \sum_{j=1}^{J} \gamma_{j t} \geq 1, \quad t=1,2, \ldots, T \\
& \mathrm{ROI}_{\min }^{f} \times \lambda_{f j g t} \leq \mathrm{ROI}_{j g}, \quad j=1,2, \ldots, J, \quad g=1,2, \ldots, G, \quad t=1,2, \ldots, T, \quad f=1,2, \ldots, F \\
& \mathrm{TRLb}_{f} \times \lambda_{f j g t} \leq \mathrm{TRL}_{j g t}, \quad j=1,2, \ldots, J, \quad g=1,2, \ldots, G, \quad t=1,2, \ldots, T, \quad f=1,2, \ldots, F \\
& \mathrm{TRL}_{j g t} \times \lambda_{f j g t} \leq \mathrm{TRLe}_{f}, \quad j=1,2, \ldots, J, \quad g=1,2, \ldots, G, \quad t=1,2, \ldots, T, \quad f=1,2, \ldots, F \\
& -M\left(1-\lambda_{f j g t}\right) \leq\left(\mathrm{TRL}_{j g t}-\mathrm{TRL}_{j g(t-1)}\right)-\mathrm{TRL}_{\min }, \quad j=1, \ldots, J, \quad g=1, \ldots, G, \\
& t=1, \ldots, \mathrm{T}, \quad f=1,2, \ldots, F \\
& \gamma_{j t} \leq \sum_{g=1}^{G} \sum_{f=1}^{F} \lambda_{f j g t} \leq \gamma_{j t} \times M, \quad j=1,2, \ldots, J, \quad t=1,2, \ldots, T \\
& \sum_{f=1}^{F} \sigma_{f j g} \leq 1, \quad j=1,2, \ldots, J, \quad g=1,2, \ldots, G \\
& \sigma_{f j g} \leq \sum_{t=1}^{T} \lambda_{f j g t} \leq K \times \sigma_{f j g}, \quad j=1,2, \ldots, J, \quad g=1,2, \ldots, G, \quad f=1,2, \ldots, F \\
& \sum_{h \in I_{g} \cup g} \sum_{f=1}^{F} \sigma_{f j h} \leq 1, \quad j=1,2, \ldots, J, \quad I_{g} \subseteq\{1, \ldots, G\}
\end{aligned}
$$




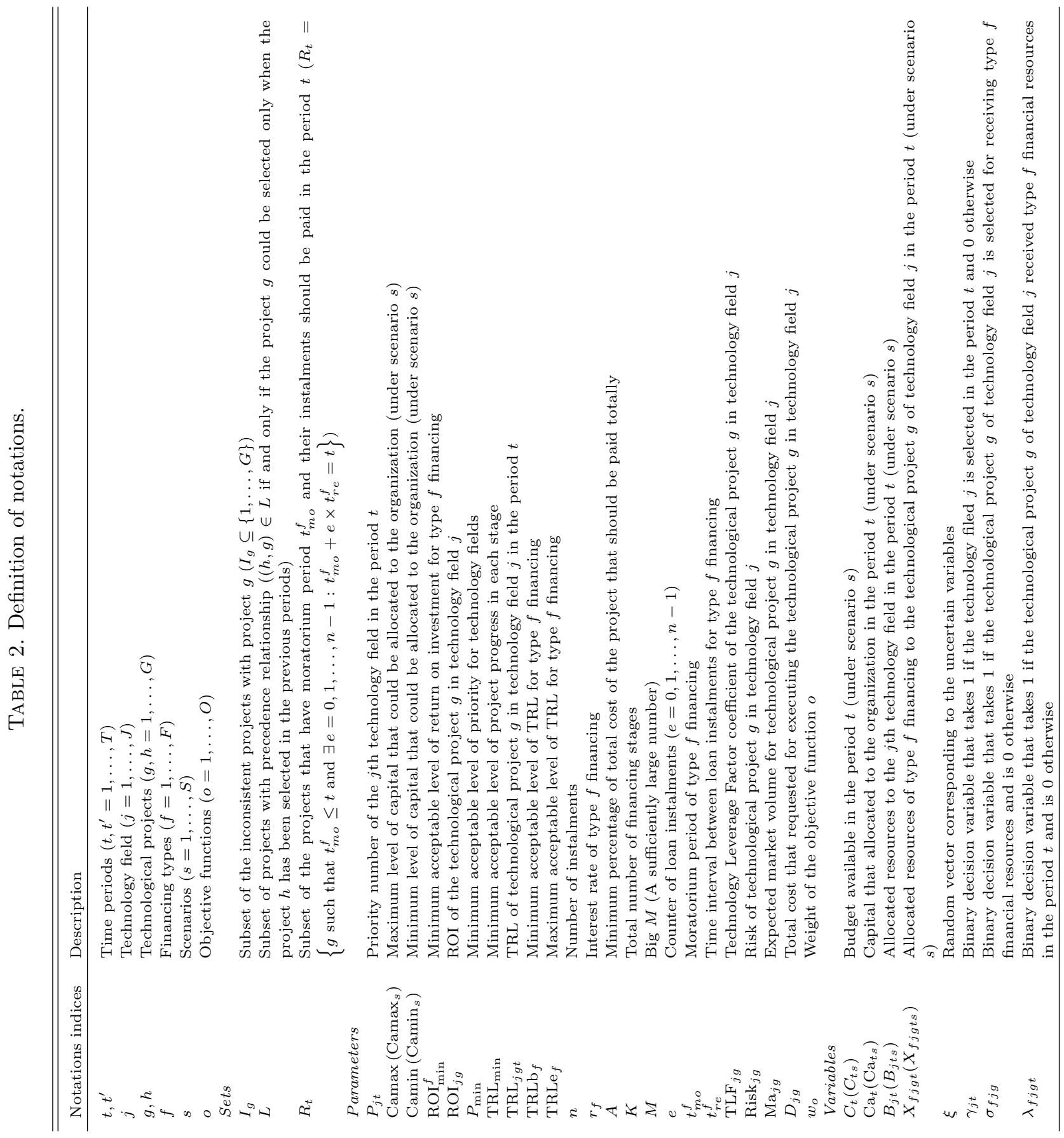




$$
\begin{aligned}
& \sum_{f=1}^{F} \lambda_{f j g t} \leq \sum_{t^{\prime}=1}^{t-1} \sum_{f=1}^{F} \lambda_{f j h t^{\prime}}, \quad t=2, \ldots, T, \quad j=1,2, \ldots, J, \quad(h, g) \in L \\
& \gamma_{j t}, \sigma_{f j g}, \lambda_{f j g t} \in\{0,1\}
\end{aligned}
$$

where $w_{1}$ and $w_{2}$ are the weights of the first and second objective functions, respectively, $Z_{1}=\sum_{j=1}^{J} \sum_{g=1}^{G} \sum_{f=1}^{F} \mathrm{Ma}_{j g} \times \mathrm{TLF}_{j g} \times \sigma_{f j g}$ and $Z_{2}=Q\left(\gamma_{j t}, \sigma_{f j g}, \lambda_{f j g t}, \xi\right)$ is the optimal value of the following problem:

Min $Z_{2}=\sum_{j=1}^{J} \sum_{g=1}^{G} \sum_{t=1}^{T} \sum_{f=1}^{F} \sum_{s=1}^{S} \operatorname{Risk}_{j g} \times X_{f j g t s}$

s.t.

$$
\begin{aligned}
& \sum_{g=1}^{G} \sum_{f=1}^{F} X_{f j g t s} \leq B_{j t s}, \quad j=1,2, \ldots, J, \quad t=1,2, \ldots, T, \quad s=1,2, \ldots, S \\
& \sum_{t=1}^{T} X_{f j g t s} \leq D_{j g} \times \sigma_{f j g}, \quad j=1,2, \ldots, J, \quad g=1,2, \ldots, G, \quad f=1,2, \ldots, F, \quad s=1,2, \ldots, S \\
& \sum_{t=1}^{T} X_{f j g t s} \geq A \times D_{j g} \times \sigma_{f j g}, \quad j=1,2, \ldots, J, \quad g=1,2, \ldots, G, \quad f=1,2, \ldots F, \quad s=1,2, \ldots, S \\
& X_{f j g t s} \leq D_{j g} \times \lambda_{f j g t}, \quad j=1,2, \ldots J, \quad g=1,2, \ldots, G, \quad t=1,2, \ldots T, \quad f=1,2, \ldots F \\
& \quad s=1,2, \ldots, S \\
& \sum_{j=1}^{J} B_{j t s} \leq C_{t s}, \quad t=1,2, \ldots T, \quad s=1,2, \ldots, S \\
& B_{j t s} \leq \gamma_{j t} \times M, \quad j=1,2, \ldots J, \quad t=1,2, \ldots T, \quad s=1,2, \ldots, S \\
& \mathrm{Camin}_{s} \leq \mathrm{Ca}_{t s} \leq \mathrm{Camax}_{s}, \quad t=1,2, \ldots T, \quad s=1,2, \ldots, S \\
& C_{t s}=\mathrm{Camin}_{s}, \quad t=1, \quad s=1,2, \ldots, S \\
& C_{t s}=C_{(t-1) s}-\sum_{j=1}^{J} \sum_{g=1}^{G} \sum_{f=1}^{F} X_{f j g t s}+\mathrm{Ca}_{t s}+\sum_{j=1}^{J} \sum_{g \in R_{t}}\left(\frac{\frac{\sum_{t^{\prime}=1}^{t-1} \sum_{f=1}^{F} X_{f j g t^{\prime} s} \times r_{f}}{n}+\sum_{f=1}^{F} X_{f j g t^{\prime} s}}{n}\right) \\
& \quad t=2, \ldots T, \quad s=1,2, \ldots, S \\
& X_{f j g t s}, C_{t s}, \mathrm{Ca}_{t s}, B_{j t s} \geq 0 .
\end{aligned}
$$

This model determines the prioritized technology fields, the selected technological projects in those technology fields, and the amount of the resources that should be allocated to the technological projects in each stage of financing.

Since the high-tech export market is an important index in the assessment and rankings of the countries' innovative performance, our model objectives are about maximizing export market and minimizing risk.

The first objective function (that is based on the certain parameters and has been shown in the first part of the Eq. (3.11)) is about maximizing the reward of the technology portfolio. According to the Terrile et al. [45], the reward of technology is associated with the Technology Leverage Factor (TLF) and its market. TLF is a measure of the potential leverage a technology could have for creating the market and is determined based on the Table 3.

The second objective function (that is scenario-based and has been shown in the second part of the Eq. (3.11) and in Eq. (3.24)) is about minimizing the risk of technological projects. 
TABLE 3. TLF description (Own construction based on [45]).

\begin{tabular}{llc}
\hline \hline $\mathrm{TLF}_{j g}$ level & Description & $\mathrm{TLF}_{j g}$ coefficient (\%) \\
\hline Low & Component level technology & 10 \\
Medium & Subsystem level technology & 30 \\
High & System level technology & 70 \\
Enabling & Enabling level technology & 100 \\
\hline
\end{tabular}

Constraint (3.12) ensures only the technology fields present on the portfolio that their respective priority number (adopted from the phase 1) is higher than the minimum acceptable priority level. Constraint (3.13) shows that there should be selected at least one technology field in each period. Constraint (3.14) guarantees that return on investment of the selected technological projects is greater than the minimum and acceptable level of return on investment for each financing type. Technology Readiness Level (TRL) constraint for technological projects are demonstrated in the equations (3.15) and (3.16). Mankins [24] has defined TRLs in 9 levels from "Basic principles" to "Actual system" (Fig. 3).

As seen in Figure 3, TRL 1 and TRL 2 correspond to the research and development (R\&D) phases and usually are financed by universities or science funds. TRL 3-TRL 9 involve technology development in the laboratory environment to the actual operational environment. These phases are financed by technology development funds (TDFs). Our model is for TDFs that finance only technology development phases, not R\&D phases (i.e. TRL 3TRL 9). These funds use different financing methods to finance technological projects according to their TRL and their financial needs. In this regard, constraints ((3.15) and (3.16)) ensure that the TRL of the selected projects in period $t$ is above the minimum acceptable level of TRL for type $f$ financing and below the maximum acceptable level of TRL for type $f$ financing. According to the constraint (3.17) if there is a minimum acceptable progress in the project (that would be assessed by the comparison of the TRL in two consecutive periods), its financing will be continued, otherwise, the financing will be stopped in the future periods. Constraint (3.18) guarantees that the technological projects are selected only when their respective technology field has been selected, and if a technological field is selected, at least one project in that field is selected and financed.

Constraint (3.19) demonstrate that each project could be financed by one of the financing methods. Constraint (3.20) ensures that a project is selected only when its corresponding technology field has been selected and the selected project could be financed in $K$ stages.

If there is an inconsistency between specific projects the constraint (3.21) should be added to the model. If $I_{g} \subseteq\{1, \ldots, G\}$ denotes the subset of the inconsistent projects with project $g$, this constraint ensures that only one of these projects could be selected. Constraint (3.22) shows the precedence relationship of projects. $L$ is defined as a subset of projects with a precedence relationship and $(h, g) \in L$ if and only if the project $g$ could be selected only when the project $h$ has been selected in the previous periods. The decision variables of the first stage, that are binary or non-negative variables, has been shown in the constraint (3.23).

The measures such as VaR or CVaR consider only on the financial risk [26]. But financing R\&D and technological projects involve three major types of risks: technology risks, market risks and financial risks $[1,32]$. So, in order to minimize the risk in the second objective function of the model (3.24), at first, a risk measure is defined based on the relationship proposed by Mokhtarzadeh et al. [30]. The $r m_{j g}, r t_{j g}, r f_{j g}$ has been defined as the market, technology, and financial risks of the project $g$ in the technological field $j$ with a corresponding weight of $w m_{j g}, w t_{j g}, w f_{j g}$, respectively.

To calculate the risk measure for each project, a risk matrix could be used, that shows the risk probability and risk impact. The risk matrix has two different dimensions: (1) "Risk probability" is about "how likely a given project will fail from the market, technology and financial aspects". (2) "Risk impact" is about "the effects of the project failure". The high risk corresponds to the high "risk impact" and high 


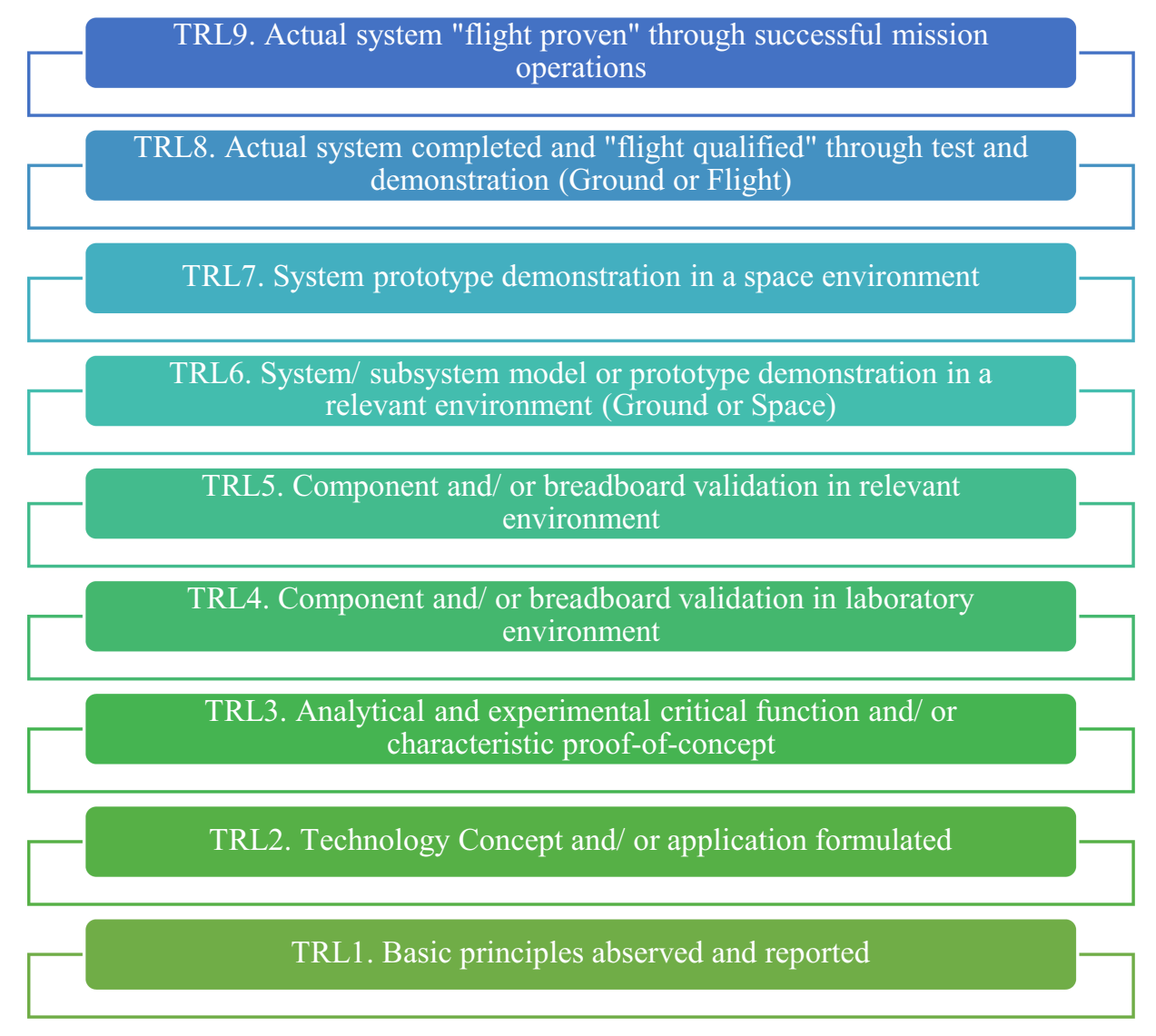

Figure 3. Technology readiness levels definition [24].

"risk probability". $r m_{j g}, r t_{j g}, r f_{j g}$ are calculated by the following equations:

$$
\begin{aligned}
r m_{j g} & =\text { market risk probability } \times \text { market risk impact } \\
r t_{j g} & =\text { technology risk probability } \times \text { technology risk impact } \\
r f_{j g} & =\text { financial risk probability } \times \text { financial risk impact } .
\end{aligned}
$$

In order to compute the risks' weights corresponding to each technological project, a pairwise comparison matrix and the linear normalization method has been used [41]. The Pairwise Comparison Scale shown in Table 4 could have been used and determine the relative importance of each pair. In this regard, the rows and columns of the $W$ matrix show the weights of the market, technology, and financial risks, respectively. For example, if the technology risk is much more important than market risk, $w_{21}$ takes 9 and the reciprocal index $\left(w_{12}\right)$ would be $\frac{1}{9}$.

$$
W=\left[\begin{array}{lll}
1 & w_{12} & w_{13} \\
w_{21} & 1 & w_{23} \\
w_{31} & w_{32} & 1
\end{array}\right]
$$

Once the $W$ matrix is built, the normalized pairwise comparison matrix $\left(W_{\text {norm }}\right)$ could be determined. Each array of the normalized matrix is calculated by the equation (3.39).

$$
\bar{w}_{l m}=\frac{w_{l m}}{\sum_{l=1}^{3} w_{l m}} .
$$


TABLE 4. Pairwise comparison scale (adopted form [41]).

\begin{tabular}{|c|c|c|}
\hline Scale of pairwise comparison & Numeric rating & Reciprocal (Inverse) \\
\hline Equal importance & 1 & 1 \\
\hline Moderate importance & 3 & $\frac{1}{3}$ \\
\hline Strong importance & 5 & $\frac{1}{5}$ \\
\hline Very strong importance & 7 & $\frac{1}{7}$ \\
\hline Extreme importance & 9 & $\frac{1}{9}$ \\
\hline Intermediate values & $2 \quad 4 \quad 6$ & $\frac{1}{2} \quad \frac{1}{4}$ \\
\hline
\end{tabular}

Then, the weight of each risk type is calculated by averaging on each row of the $W_{\text {norm }}$ matrix (Eq. (3.40)) .

$$
w_{\text {final }}=\frac{\sum_{m=1}^{3} \bar{w}_{l m}}{3} .
$$

The total risk for each technological project, composed of market, technology, and financial risks, is calculated by the equation (3.41):

$$
\operatorname{Risk}_{j g}=w m_{j g} r m_{j g}+w t_{j g} r t_{j g}+w f_{j g} r f_{j g} .
$$

So, the risk numbers $\left(r m_{j}, r t_{j}, r f_{j}\right)$, their weights $\left(w m_{j}, w t_{j}, w f_{j}\right)$, and the total risk $\left(\operatorname{Risk}_{j g}\right)$ are in $[0,1]$ interval. Finally, The second objective function, that is about minimizing the risk and is scenario-based is as equation (3.24).

The total budget of a field in each period constrains the sum of financing for technological projects of that field and this has been shown in the constraint (3.25). According to the constraint (3.26) the sum of staged financing should be less than or equal to the project's cost and in constraint (3.27) it has been shown that the total financing of the project should be greater than the determined minimum level. Constraint (3.28) ensures that the financing in each period is done only when the project should be financed at that period.

Constraint (3.29) is about this fact that the total amount that is allocated to technology fields in each period should be lower than the total budget available in that period. Because the budget allocation to each technology field is done only when that field is selected, the constraint (3.30) has been added to the model. It is assumed that in each period some part of the state budget is allocated to the TDF and there is a minimum and maximum level for that. This has been formulated in the constraint (3.31). Constraint (3.32) shows the available budget in the first period.

The effect of the different moratorium periods has been considered in the equation (3.33) that calculates the budget available in each period by considering the loans repayments. With considering reinvestment, the loans' repayments after their moratorium period will be added to the available budget. In this constraint of the model, it has been defined a subset of the projects that have moratorium period $t_{m o}^{f}$ and their instalments should be paid in the period $t\left(R_{t}=\left\{g\right.\right.$ such that $t_{m o}^{f} \leq t$ and $\left.\exists e=0,1, \ldots, n-1: t_{m o}^{f}+e \times t_{r e}^{f}=t\right\}$. So, the constraint (3.33) has been added to the model.

Finally, the decision variables of the second stage, that are non-negative variables, has been shown in the constraint (3.34).

\section{Solution Method}

As the maximum and minimum level of capital that could be allocated to the organization (Camax and Camin) are continuous stochastic parameters in our problem, solving it by considering all scenarios that means unlimited number of test scenarios, is indeed impossible. In addition, the complicated multi-period nature of the 
proposed two-stage stochastic model makes it an "NP-hard" problem that it is difficult to solve by exact methods, particularly by increasing the number of scenarios and planning periods. Sample Average Approximation (SAA) is a Monte Carlo simulation-based approach that often is used in order to solve large scale stochastic optimization problems. This method is about scenario-reduction and is based on sampling from the scenarios and could be used to cope with the NP-hardness. In the SAA method the objective function value is approximated using an estimation of the sample average that is derived from a random sample.

\subsection{Sample Average Approximation (SAA)}

Rubinstein and Shapiro $[36,37]$ is one of the first references that has used the SAA method with fixed sample size in all iterations and referred to it as "stochastic counterpart method". Gurkan et al. [12] also have used this method and referred to as "sample-path approximation method". In order to solve the stochastic optimization problems, the later studies have used variable sample size in SAA. Homem-De-Mello [14] has provided a variablesample framework for solving a discrete stochastic optimization problem. Based on the Emelogu et al. [8], the basic idea of SAA is that a random sample is generated, and an approximation of the expected value is done by considering the corresponding sample average function. This procedure is repeated several times until the pre-specified stopping criterion is satisfied.

In this section, an illustration of the SAA method is presented based on Emelogu et al. [8]. Consider the following two-stage stochastic optimization model:

$$
\operatorname{Min} Z^{*}=\min _{x \in X} c^{T} x+E_{p}[Q(x, \xi(\omega))]
$$

where

$$
Q(x, \xi(\omega))=\min _{y \geq 0}\left\{q(\omega)^{T} y \mid D y \geq h(\omega)-T(\omega) x\right\}
$$

in which $x$ shows the first-stage decisions that should be made prior to the realization of a scenario $(\omega \in \Omega)$, that is known when the second-stage decisions $y$ are made. $Q(x, \xi(\omega))$ is the optimal value of the secondstage problem with the parameters $\xi(\omega)=(q(\omega), h(\omega), T(\omega))$. $\Omega$ contains scenarios $\left\{\omega_{1}, \omega_{2}, \ldots, \omega_{|\Omega|}\right\}$ with corresponding probabilities $\left\{p_{n}\right\} ; n=1,2, \ldots,|\Omega| . E[Q(x, \xi(\omega))]$ could be explained as follows:

$$
E[Q(x, \xi(\omega))]=\sum_{n=1}^{|\Omega|} p_{n} \times Q\left(x, \xi\left(\omega_{n}\right)\right) .
$$

In this model, the number of scenarios grows exponentially with the size of the problem. To overcome this issue, the exterior sampling method of SAA is used to solve the deterministic equivalent problem. In SAA a sample $\omega_{1}, \omega_{2}, \ldots, \omega_{N}$ of $N$ sample scenarios are generated from the scenario set $\Omega$ based on the probability distribution $P$ and then $E[Q(x, \xi(\omega))]$ is calculated by the sample average function $\sum_{n=1}^{N} \frac{1}{N} \times Q\left(x, \xi\left(\omega_{n}\right)\right)$. The corresponding SAA problem could be written as follows:

$$
Z^{N}=\min _{x \in X} c^{T} x+\frac{1}{N} \sum_{n=1}^{N} Q\left(\widehat{x}, \xi\left(\omega_{n}\right)\right)
$$

in which $Z^{N}$ and $\widehat{x}$ estimate the optimal solution and value of their true counterparts in the stochastic program in equation (4.1).

Solving a stochastic problem using SAA involves the following steps: 
Generate $M$ independent samples each of size $N$ and solve the corresponding SAA model.

Step 1.

$$
Z^{N}=\min _{x \in X} c^{T} x+\frac{1}{N} \sum_{n=1}^{N} Q\left(\widehat{x}, \xi\left(\omega_{n}\right)\right) .
$$

Let $Z_{m}^{N}$ and $X_{m}^{N}$ be the corresponding optimal solutions and optimal values; $m=1,2, \ldots, M$.

Step 2. Compute

$$
\begin{aligned}
\bar{Z}_{M}^{N} & =\frac{1}{M} \sum_{m=1}^{M} Z_{m}^{N} . \\
\sigma_{Z_{M}^{N}}^{2} & =\frac{1}{(M-1) \times M} \sum_{m=1}^{M}\left(Z_{m}^{N}-\bar{Z}_{M}^{N}\right)^{2} .
\end{aligned}
$$

The expected value of $Z^{N}$ is less than or equal to the optimal value of $Z^{*}$ of the true counterpart problem, $\bar{Z}_{M}^{N}$ provides a lower statistical bound for $Z^{*}$ and $\sigma_{Z_{M}^{N}}^{2}$ shows the variance of this estimator.

Step 3. Select a feasible first stage solution of the true problem $(\widehat{x} \in X)$ and make an estimation for the objective function of the original problem by using a different sample $N^{\prime}$. Now, the true objective function value is as follows:

$$
Z^{N^{\prime}}(\widehat{x})=c^{T} \widehat{x}+\frac{1}{N^{\prime}} \sum_{n=1}^{N^{\prime}} Q\left(\widehat{x}, \xi\left(\omega_{n}\right)\right)
$$

in which $\left\{\omega_{1}, \omega_{2}, \ldots, \omega_{N^{\prime}}\right\}$ is a sample with size $N^{\prime}$ and $N^{\prime}$ is chosen to be much larger than $N . Z^{N^{\prime}}(\widehat{x})$ is an unbiased estimator of $c^{T} \widehat{x}+E[Q(\widehat{x}, \xi(\omega))]$ and for any feasible solution we have $E\left[Z^{N^{\prime}}(\widehat{x})\right] \geq Z^{*}$. The variance of this estimate is as follows:

$$
\sigma_{Z^{N^{\prime}}(\widehat{x})}^{2}=\frac{1}{\left(N^{\prime}-1\right) \times N^{\prime}} \sum_{n=1}^{N^{\prime}}\left(c^{T} \widehat{x}+Q\left(\widehat{x}, \xi\left(\omega_{n}\right)\right)-Z^{N^{\prime}}(\widehat{x})\right)^{2} .
$$

Step 4. By using the following equation, calculate an estimation of the optimality gap for the solution $\widehat{x}$ using the lower and upper bound estimates, through estimators computed in steps 2 and 3 :

$$
\operatorname{Gap}_{N, M, N^{\prime}}(\widehat{x})=Z^{N^{\prime}}(\widehat{x})-\bar{Z}_{M}^{N} .
$$

The variance of the gap is estimated by:

$$
\sigma_{\text {gap }}^{2}=\sigma_{Z^{N^{\prime}}(\widehat{x})}^{2}+\sigma_{Z_{M}^{N}}^{2} .
$$

Step 5. Choose $\widehat{x}^{*}$ as an optimal solution that has the smallest objective value:

$$
\widehat{x}^{*} \in \operatorname{argmin}\left\{Z^{N^{\prime}}(\widehat{x}): \widehat{x} \in\left\{\widehat{x}^{1}, \widehat{x}^{2}, \ldots \widehat{x}^{M}\right\}\right\} .
$$

\section{Case study: Technology portfolio Selection in IPF}

This model was developed by the focus on Iran's TDF: "Innovation \& Prosperity Fund (IPF)". The main goal of establishing IPF is to improve country's position in the knowledge-based economy by enhancing advanced technologies level through supporting commercialization activities in innovative and knowledge-based companies. Knowledge-based products and services that should be supported by IPF include 8 technology fields: (1) Biotechnology; (2) Advanced Materials and Polymer and Chemical Products; (3) Power and Electronic Hardware, Laser 
and Photonics; (4) ICT \& Computer Software; (5) Advanced Machinery and Equipment; (6) Advanced Drugs; (7) Medical Instrument, Appliances, and Equipment; (8) Advanced Products in Other fields.

IPF has provided more than 500 million $\$$ financial facilities for about 3000 knowledge-based companies in the last 4 years. As there is no technology priority defined in high-level strategies to support knowledge-based fields, IPF allocated its financial resources without any specific limit or priority for different technology fields. Also, there was no attention to these technologies' role and impact in the knowledge-based economy in resource allocation. Therefore, the resources of the IPF have not optimally allocated to the knowledge-based fields on the one hand, and questions raise about the IPF performance and resource allocation method on the other hand. So, our proposed model is developed and used in order for technology portfolio selection and optimal resource allocation to technological projects in IPF.

\subsection{Data}

In the first step based on the proposed BWM method, the priority number of different technology fields was calculated for each period. For this purpose, a questionnaire was developed for pairwise comparisons and distributed between C-level managers of IPF. After gathering their opinion, the BWM model was run by using GAMS 24.1.2 software (MIP Solver). Validity and reliability in BWM method are determined by "consistency index" $\left(\xi^{L *}\right)$ that should be near the zero. The consistency index for all pairwise comparisons of the model was between 0.04 and 0.09 . So, the calculated priority numbers are rational and acceptable. The weights of the criteria and sub-criteria have been shown in Appendix A.

After determining the criteria weights, it has been calculated the priority number of technology fields by multiplying the weight in the corresponding score of the technology fields (based on the DMs opinion). The results have been provided in Appendix B.

In the second step, planning for 12 periods and 8 technology fields was considered and the number of technological projects is among 10-30 for each technology field. There is considered two different financing types that their interest rate is $4 \%$ and $11 \%$ accordingly and their repayment period is 3 years and 5 years. Staged financing is done in three stages with regard to the technical progress assessment results, moratorium period for loans is considered 2 periods and their repayment should be done in 3 stages. The problem parameters are presented in Appendix C. There were three sets of interdependent projects and three sets of inconsistent projects (Appendix D). Inconsistent projects could not be selected and started in the same period.

\subsection{Computational results}

In order to determine the best method to solve the bi-objective model with the SAA approach, some meetings with the experts have been held and according to their opinion the weighted objective function method has been selected and used (as seen in Eq. (3.11)). The results of the implementation of our model in the real case study are presented in this section. These results are obtained by the GAMS 24.1.2 (Cplex solver) on a laptop with Intel Core i5 processor with $1.6 \mathrm{GHz}$ of CPU and 4 GB Ram.

As explained in the Section 4.1, in order to solve this stochastic problem by SAA, different size of the sample $(N)$ and several iterations $(M)$ for each sampling is considered to gain the lower bound of the optimum point. For calculating the upper bound a sample size should be considered that is much larger than the previous samples $\left(N^{\prime}\right)$. Therefore, in this problem, it has been considered different scenario numbers; i.e. $N=20,30$, 50,100,150, 200 and $M$ and $N^{\prime}$ is considered 10 and 1500, respectively. Then, the optimality gap has been calculated by the equation (4.10). The solution that has the minimum optimality gap, is the optimal solution.

The model dimensions have been presented in Tables 5 and 6 shows the computational results of solving the problem.

As seen below the minimum optimality gap belongs to the row 3 that considers 30 scenarios for uncertain parameters. As the number of iterations $(M)$ is constant and the results are reported after 10 iterations, the SAA method with a modest number of scenarios can provide high-quality solutions and by increasing the number of scenarios and consequently increasing the model complexity, the results have been worsened. 
TABLE 5. The model dimensions.

\begin{tabular}{|c|c|c|c|c|c|c|}
\hline \multirow[t]{2}{*}{ Row } & \multirow{2}{*}{$\begin{array}{l}\text { The number of scenarios } \\
N\end{array}$} & \multicolumn{3}{|c|}{ The number of variables } & \multirow[t]{2}{*}{ Execution time (s) } & \multirow{2}{*}{$\begin{array}{l}\text { The number } \\
\text { of constraints }\end{array}$} \\
\hline & & Binary & Continuous & Total & & \\
\hline 1 & 1 (exact model) & & 2050 & 4490 & 6.562 & 13665 \\
\hline 2 & 20 & & 41000 & 43440 & 7.781 & 106765 \\
\hline 3 & 30 & & 61500 & 63940 & 7.406 & 155765 \\
\hline 4 & 50 & 2440 & 102500 & 104940 & 8.719 & 253765 \\
\hline 5 & 100 & & 205000 & 207440 & 10.828 & 498765 \\
\hline 6 & 150 & & 307500 & 309940 & 15.094 & 743765 \\
\hline 7 & 200 & & 410000 & 412440 & 18.329 & 988765 \\
\hline 8 & $N^{\prime}=1500$ & 2440 & 3075000 & 3077440 & 135.214 & 7358565 \\
\hline
\end{tabular}

TABLE 6. Objective values and main decision variables.

\begin{tabular}{|c|c|c|c|c|c|c|c|c|c|}
\hline \multirow[t]{2}{*}{ Row } & \multirow{2}{*}{$\begin{array}{l}\text { The num- } \\
\text { ber of sce- } \\
\text { narios } \\
N\end{array}$} & \multicolumn{3}{|c|}{ Objective function values } & \multicolumn{2}{|l|}{ Optimality Gap } & \multicolumn{3}{|c|}{ Decision variables } \\
\hline & & $Z_{1}$ & $Z_{2}$ & $Z^{*}$ & $\operatorname{Gap}_{N, M, N^{\prime}}(\widehat{x})$ & $\sum_{t} \gamma_{j t}$ & $\sum_{f, j, g} \sigma_{f j g}$ & $\begin{array}{c}\sum_{j, g, t} \\
f=1\end{array}$ & $\begin{array}{l}\text { fjgts } \\
f=2\end{array}$ \\
\hline 1 & $\begin{array}{l}1 \text { (exact } \\
\text { model) }\end{array}$ & 69.650 & 31.677 & 105.002 & - & 8 & 25 & 7.63 & 13.05 \\
\hline 2 & 20 & 14.855 & 17.423 & 119.937 & -0.384 & 6 & 10 & 4.97 & 40.81 \\
\hline 3 & 30 & 12.730 & 14.072 & 119.324 & 0.229 & 4 & 8 & 4.83 & 32.48 \\
\hline 4 & 50 & 10.730 & 15.950 & 121.263 & -1.71 & 3 & 6 & 4.83 & 21.07 \\
\hline 5 & 100 & 7.770 & 20.601 & 125.068 & -5.515 & 3 & 4 & 4.83 & 13.72 \\
\hline 6 & 150 & 7.770 & 30.901 & 130.218 & -10.665 & 3 & 4 & 4.83 & 13.72 \\
\hline 7 & 200 & 7.770 & 41.201 & 135.369 & -15.816 & 3 & 4 & 4.83 & 13.72 \\
\hline 8 & $N^{\prime}=1500$ & 11.950 & 13.786 & 119.553 & - & 4 & 8 & 4.90 & 31.95 \\
\hline
\end{tabular}

The optimal composition and timing of the technological projects portfolio, their staged financing, moratorium period, and the repayment period is shown in Figure 4. This result corresponds to the row 3 of Table 6 .

The main implications of Figure 4 are as follows:

- Staged financing strategy: The financing of projects is done based on their assessment in each stage and some projects financing has been stopped because they did not have sufficient technical progress in each stage. For example, P15, P27, and P18 from technology fields 3, 4, and, 6 respectively, have not had technical progress and their financing have stopped after one stage.

- Selection of inconsistent projects: In technology field 4, only P18 has been selected, and inconsistent project in that technology field (P3) has not been selected.

- Moratorium period: The model takes into account two periods after the projects' financing as the moratorium period and repayment starts after that.

- Repayment period: Loans repayment starts after the moratorium period and repayments are done in twoperiod intervals.

- Different financing types: The model determines the best financing method for each project and each project could be financed only by one method. With "different financing type" we mean loans with different interest rate, different moratorium and repayment periods. 


\begin{tabular}{|c|c|c|c|c|c|c|c|c|c|c|c|c|}
\hline Financing Type. Technology Field. Project & $t_{1}$ & $t_{2}$ & $t_{3}$ & $t_{4}$ & $t_{5}$ & $t_{6}$ & $t_{7}$ & $t_{8}$ & $t_{9}$ & $t_{10}$ & $t_{11}$ & $t_{12}$ \\
\hline 1.4 .18 & & & & & & & & & & & & \\
\hline 2.3 .15 & & & & & & & & & & & & \\
\hline 2.4 .27 & & & & & & & & & & & & \\
\hline 2.4 .30 & & & & & & & & & & & & \\
\hline 2.6 .16 & & & & & & & & & & & & \\
\hline 2.6 .18 & & & & & & & & & & & & \\
\hline 2.8 .16 & & & & & & & & & & & & \\
\hline 2.8 .19 & & & & & & & & & & & \\
\hline \\
\hline
\end{tabular}

FigURE 4. Technological projects Financing period, Moratorium period and repayments.

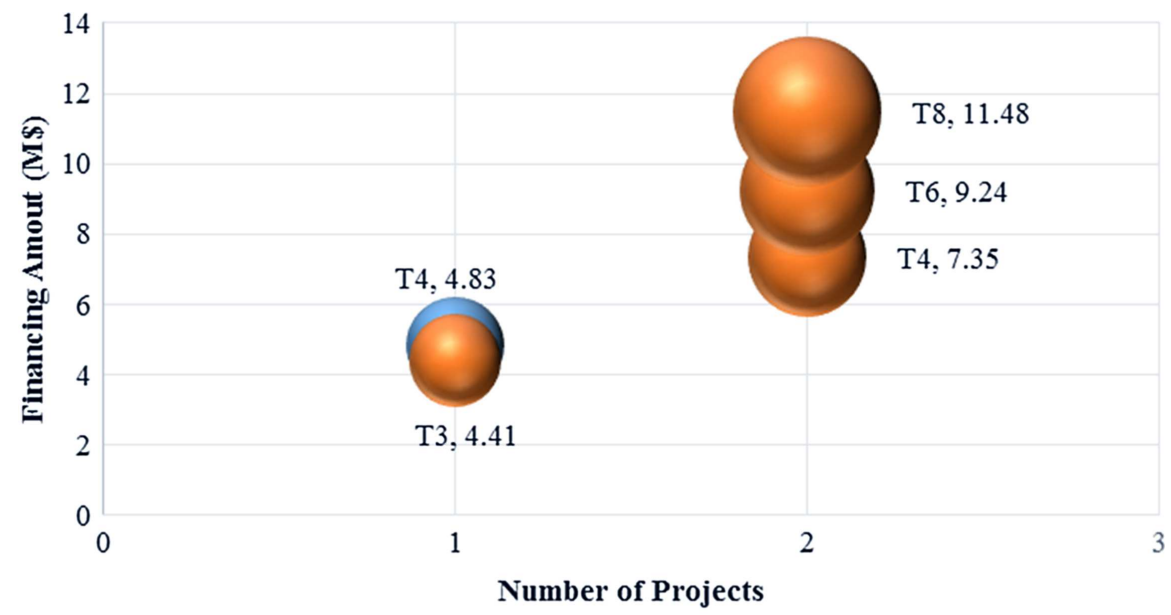

- Type 1 Financing $\odot$ Type 2 Financing

FiguRE 5. Total financing and total approved projects by financing type and technology field.

\subsection{Results analysis}

In this section, the results corresponding to row 3 of Table 6 are analyzed with more details. Figure 5 shows total financing and total approved projects by technology fields and financing type. As seen in Figure 5, technology field 1 (biotechnology), 2 (advanced materials and polymer and chemical products), 5 (advanced machinery and equipment) and 7 (medical instrument, appliances, and equipment) have not selected because of their low priority number. Technology field 4 (ICT \& computer software) has attracted the most financing. Because, this field has a large export market potential and with regard to the widespread application of ICT, "TLF" of this field is greater than the other fields. Technology field 8 (advanced products in other fields) and technology field 6 (advanced drugs) have the second and third ranks in terms of total financing. These fields include industries with great potential for high-tech export. Most of the projects received type 2 financing that has a greater interest rate. These projects are larger projects with larger potential market and greater ROI.

Figure 5 also shows the total approved projects in each field by financing type. The maximum number of approved projects belong to technology field 4 (ICT \& computer software) with 1 approved projects for type 1 financing and 2 approved projects for type 2 financing. 


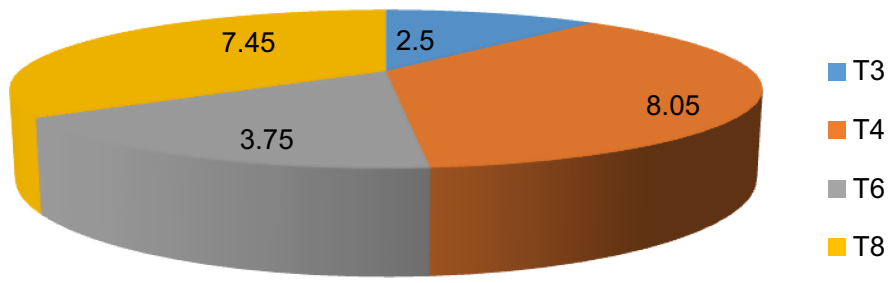

Figure 6. Export market by technology field.

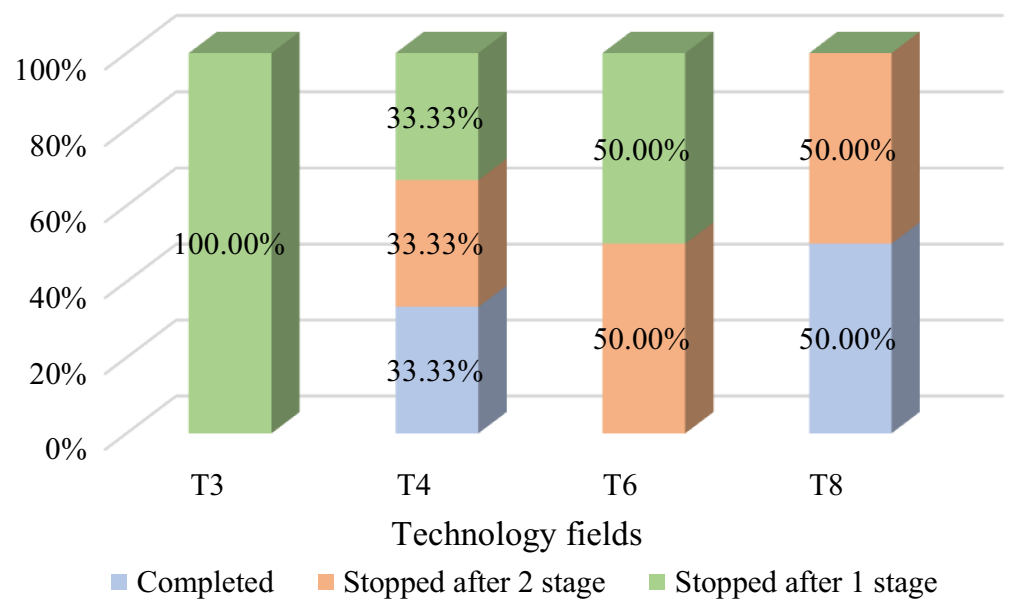

FiguRE 7. The proportion of completed projects to the total number of approved projects.

The technology fields have been compared in terms of export market, too. Figure 6 shows the potential export market by technology field. As it seen, technology field 4, which has attracted the greatest financial resources and more projects have approved in this field, has the greatest export market. In contrast in technology field 3 (power and electronic hardware, laser and photonics), there is little export opportunities, due to the presence of large and strong companies across the world.

In order to compare the performance of the companies in different technology fields, it has been defined two metrics: "The proportion of completed projects to the total number of approved projects" and "The proportion of completed projects to total financing" in each technology field. By "completed projects" we mean projects that have had enough technical progress in each stage and their financing has done in all 3 stages. As seen in Figure 7, the most number of completed projects belong to technology field 8 (advanced products in other fields) and then technology field 4 (ICT \& computer software). The companies in technology field 3 (power and electronic hardware, laser and photonics) have the weakest performance in terms of this index. It's interesting and shows that a large number of firms start complicated projects in the hardware, laser and photonics field, but fail to enhance their technology readiness level and finish their projects successfully.

In terms of the second metric, as seen in Figure 8, technology field 8 (advanced products in other fields) has the best performance and the companies in this field executed their projects more successfully. Firms in the technology field 3 and 6 have the worst performance and the project's completion rate in these fields is zero (Fig. 8).

It also has been done sensitivity analysis for different values of $\mathrm{ROI}_{\min }^{f}, P_{\min }$ and $A$ The results are shown in Tables 7-9. These analyzes are done for $N=30$ scenarios. 


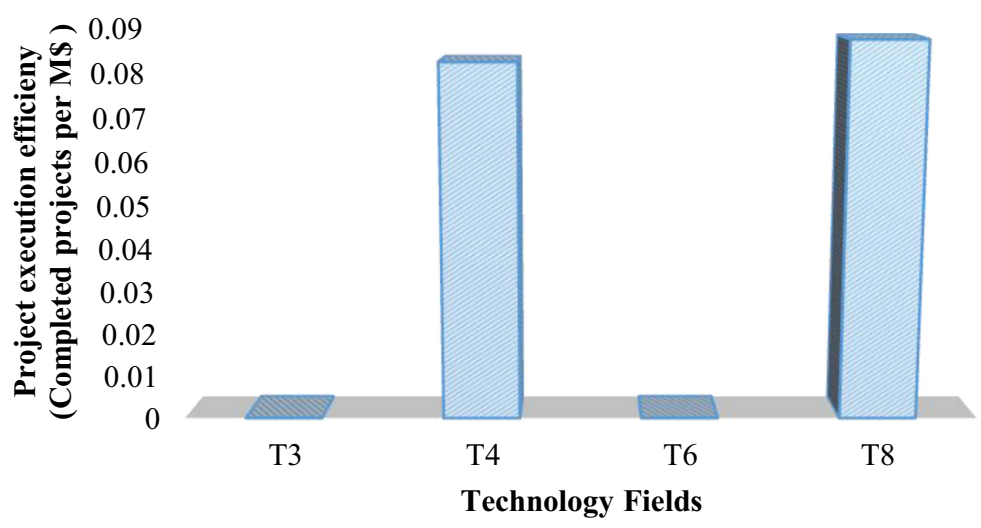

FiguRE 8. The proportion of completed projects to total financing.

TABLE 7. Sensitivity analysis for ROI.

\begin{tabular}{llllllllll}
\hline \hline \multirow{2}{*}{ Row } & \multicolumn{3}{c}{ Return on investment } & \multicolumn{3}{c}{ Objective function values } & \multicolumn{3}{c}{ Decision variables } \\
\cline { 2 - 10 } & \multicolumn{3}{c}{ ROI $_{\text {min }}$} & $Z_{1}$ & $Z_{2}$ & $Z^{*}$ & $\sum_{t} \gamma_{j t}$ & $\sum_{f, j, g} \sigma_{f j g}$ & $\sum_{j, g, t} X_{f j g t s}$ \\
\cline { 2 - 10 } & $f=1$ & $f=2$ & & & & & & $f=1$ & $f=2$ \\
\hline 1 & 0.12 & 0.19 & 11.605 & 13.762 & 119.732 & 4 & 7 & 11.83 & 23.24 \\
2 & 0.1 & 0.17 & 12.730 & 14.072 & 119.324 & 4 & 8 & 4.83 & 32.48 \\
3 & 0.09 & 0.16 & 12.730 & 14.072 & 119.324 & 4 & 8 & 4.83 & 32.48 \\
4 & 0.07 & 0.14 & 12.840 & 13.469 & 118.967 & 4 & 8 & 4.83 & 26.18 \\
\hline
\end{tabular}

TABle 8. Sensitivity analysis for $P$.

\begin{tabular}{|c|c|c|c|c|c|c|c|c|}
\hline \multirow{3}{*}{ Row } & \multirow{3}{*}{$\begin{array}{l}\text { Priority number } \\
P_{\min }\end{array}$} & \multicolumn{3}{|c|}{ Objective function values } & \multicolumn{4}{|c|}{ Decision variables } \\
\hline & & \multirow[t]{2}{*}{$Z_{1}$} & \multirow[t]{2}{*}{$Z_{2}$} & \multirow[t]{2}{*}{$Z^{*}$} & \multirow[t]{2}{*}{$\sum_{t} \gamma_{j t}$} & \multirow[t]{2}{*}{$\sum_{f, j, g} \sigma_{f j g}$} & \multicolumn{2}{|c|}{$\sum_{j, g, t} X_{f j g t s}$} \\
\hline & & & & & & & $f=1$ & $f=2$ \\
\hline 1 & 0.07 & 13.605 & 33.747 & 128.724 & 3 & 8 & 4.83 & 35.07 \\
\hline 2 & 0.09 & 12.730 & 14.072 & 119.324 & 4 & 8 & 4.83 & 32.48 \\
\hline 3 & 0.1 & 12.980 & 17.233 & 120.779 & 4 & 8 & 12.25 & 21.07 \\
\hline 4 & 0.15 & 7.455 & 15.755 & 122.803 & 4 & 5 & 0 & 20.65 \\
\hline
\end{tabular}

As seen above by increasing the $\mathrm{ROI}_{\text {min }}^{f}$ the number of approved projects is decreased, and the optimum answer is worsened.

By increasing the technology fields' priority number, technology fields with greater priority and larger projects have been selected and they have financed by type 2 financing only.

By decreasing the minimum financing level, the number of technology fields and technological projects that could be selected and financed, have increased but the optimum answer has worsened. If IPF wants to finance projects totally, it could finance only 6 projects, while by, for example, 60 percent financing, it could finance 9 projects. So, the companies' financial partnership for executing projects is very important and allows more technological projects execution in the country level. 
TABLE 9. Sensitivity analysis for $A$.

\begin{tabular}{|c|c|c|c|c|c|c|c|c|}
\hline \multirow[t]{3}{*}{ Row } & \multirow{3}{*}{$\begin{array}{l}\text { Minimum financing level } \\
A\end{array}$} & \multicolumn{3}{|c|}{ Objective function values } & \multicolumn{4}{|c|}{ Decision variables } \\
\hline & & \multirow[t]{2}{*}{$Z_{1}$} & \multirow[t]{2}{*}{$Z_{2}$} & \multirow[t]{2}{*}{$Z^{*}$} & \multirow[t]{2}{*}{$\sum_{t} \gamma_{j t}$} & \multirow[t]{2}{*}{$\sum_{f, j, g} \sigma_{f j g}$} & \multicolumn{2}{|c|}{$\sum_{j, g, t} X_{f j g t s}$} \\
\hline & & & & & & & $f=1$ & $f=2$ \\
\hline 1 & 0.6 & 14.470 & 18.722 & 120.779 & 4 & 9 & 4.14 & 33.24 \\
\hline 2 & 0.7 & 12.730 & 14.072 & 119.324 & 4 & 8 & 4.83 & 32.48 \\
\hline 3 & 0.8 & 11.730 & 13.539 & 119.557 & 3 & 7 & 13.52 & 24.08 \\
\hline 4 & 0.9 & 10.730 & 12.305 & 119.440 & 3 & 6 & 6.21 & 27.09 \\
\hline 5 & 1 & 10.730 & 13.672 & 120.124 & 3 & 6 & 6.9 & 30.1 \\
\hline
\end{tabular}

\section{MAnAGERIAL InSights}

Knowledge-based firms have an important role in technological development and knowledge economy of countries. Governments in all countries have supportive plans for this type of firms. But, regarding the financial resources' limitation, determining technology priorities and targeted resource allocation to the technological projects of knowledge-based firms is an important issue in innovation and technology policymaking. The policymakers and managers, especially in developing countries with high risks and high uncertainties, could use the proposed framework for prioritizing technology fields and then decision-making about resource allocation to the technological projects regarding their market potential and risks on the uncertain conditions. This model also could be applied for the optimization of portfolio and resource allocation to medium-tech to high-tech projects that have high-risk and high-gain. By considering this model and proposed performance indices, it would be possible to prioritize technology fields, determine a budget level for each technology field with regard to the priorities and previous performance of the related companies and allocate resources to the technological projects that have the best performance, greater market potential and lower risk (including market, technology and financial risk) level. Also, technological projects could be divided into two general types that different financing methods would be suitable for each of them:

(1) Prototyping projects: These technological projects are in the lower technology readiness level (TRL 3-5) and have a long way to go to the market. Therefore, their risk is high, and their market potential is low. Accordingly, they need to the cheaper financing and the financing method with lower interest rate would be suitable for them.

(2) Industrial production projects: These are the technological projects with lower risk (TRL 5-9) and higher market potential. For this type of projects, that have a defined market and could achieve to the appropriate income, financing with higher interest rate could be used.

\section{Conclusion}

Technology development is a costly process and states in developed and developing countries allocate a large amount of financial resources to technology commercialization, especially through Technology Development Funds (TDFs). But resources are limited and determining high priority technologies with higher impact on the country's innovative performance, has been one of the main concerns of science and technology policymakers, for a long time. Since different technologies have different impacts on the economic development, high-tech export, and country's position in innovation rankings, the optimal resource allocation to technology development is getting more attention in recent years. "Technology portfolio planning" is one of the methods that has been developed and applied in this regard.

In this study, a decision-making framework and a two-stage stochastic model was developed considering staged-financing, moratorium period, and reinvestment strategy and by combining BWM and SAA to answer 
the question of which technology fields should be supported by TDFs and how much financial resource should be allocated to different technological projects. In this regard, return on investment, risk, TRL, export market potential, and the assessment of the technical progress of projects in different stages of project execution have incorporated in a comprehensive stochastic model. Our model has important implications for technology policy making, technology prioritizing and resource allocation for the development of various technologies by TDFs in uncertain situations. The main advantages of our proposed model are considering uncertainty in decisionmaking, early signaling about underperforming technological projects via staged-financing approach and therefore enabling better management of limited financial resources by TDFs and taking into account moratorium period that did not consider in the previous works. This model also takes into consideration the reinvestment strategy and different financing methods for technological projects. Finally, considering the moratorium period and repayment period as decision variables is recommended for future research.

\section{Appendix A.}

In order to determine the priority number of different technology fields, the weights of the criteria and sub-criteria have been calculated based on the BWM model and presented in the Table A.1 below.

TABLE A.1. The weights of the criteria and sub-criteria.

\begin{tabular}{|c|c|c|c|c|c|c|}
\hline Criteria & $\begin{array}{l}\text { Criteria } \\
\text { weights }\end{array}$ & Sub-criteria (1) & $\begin{array}{l}\text { Local } \\
\text { weights } \\
\text { of sub- } \\
\text { criteria } \\
\text { (1) }\end{array}$ & Sub-criteria $(2)$ & $\begin{array}{l}\text { Local } \\
\text { weights } \\
\text { of sub- } \\
\text { criteria } \\
(2)\end{array}$ & $\begin{array}{l}\text { Global } \\
\text { weights }\end{array}$ \\
\hline \multirow[t]{7}{*}{ Benefits } & \multirow[t]{7}{*}{0.18} & \multirow[t]{5}{*}{ Economic } & \multirow[t]{5}{*}{0.60} & Market volume & 0.25 & 0.027 \\
\hline & & & & Having export market & 0.25 & 0.027 \\
\hline & & & & $\begin{array}{l}\text { Impact on productivity } \\
\text { improvement }\end{array}$ & 0.15 & 0.016 \\
\hline & & & & Value added potential & 0.20 & 0.022 \\
\hline & & & & Applications span & 0.15 & 0.016 \\
\hline & & \multirow{2}{*}{ Social } & \multirow{2}{*}{0.40} & Environmental impact & 0.35 & 0.025 \\
\hline & & & & Job creation potential & 0.65 & 0.047 \\
\hline \multirow{4}{*}{$\begin{array}{l}\text { Technological } \\
\text { aspects }\end{array}$} & \multirow[t]{4}{*}{0.25} & Patents & 0.30 & & & 0.075 \\
\hline & & $\begin{array}{l}\text { Technology type (Key, enabler, } \\
\text { etc.) }\end{array}$ & 0.15 & & & 0.038 \\
\hline & & $\begin{array}{l}\text { Prior experience in the technol- } \\
\text { ogy field }\end{array}$ & 0.25 & & & 0.062 \\
\hline & & $\begin{array}{l}\text { Synergy with other technology } \\
\text { fields }\end{array}$ & 0.30 & & & 0.075 \\
\hline \multirow[t]{3}{*}{ Resources } & \multirow[t]{3}{*}{0.20} & Required human resources & 0.30 & & & 0.060 \\
\hline & & $\begin{array}{l}\text { Required technical infrastruc- } \\
\text { ture }\end{array}$ & 0.35 & & & 0.070 \\
\hline & & Required financial resources & 0.35 & & & 0.070 \\
\hline \multirow[t]{4}{*}{$\begin{array}{l}\text { Strategic } \\
\text { aspects }\end{array}$} & \multirow[t]{4}{*}{0.27} & $\begin{array}{l}\text { Alignment with technology poli- } \\
\text { cies of the country }\end{array}$ & 0.30 & & & 0.081 \\
\hline & & $\begin{array}{l}\text { Technology importance in strate- } \\
\text { gic plans }\end{array}$ & 0.30 & & & 0.081 \\
\hline & & $\begin{array}{l}\text { International cooperation oppor- } \\
\text { tunity }\end{array}$ & 0.15 & & & 0.040 \\
\hline & & Timing (Time to market) & 0.25 & & & 0.068 \\
\hline \multirow[t]{3}{*}{ Risks } & \multirow[t]{3}{*}{0.10} & Technological risks & 0.35 & & & 0.035 \\
\hline & & Market risks & 0.30 & & & 0.030 \\
\hline & & Financial risks & 0.35 & & & 0.035 \\
\hline
\end{tabular}




\section{APPENDix B.}

After determining the criteria weights, the priority number of technology fields has been calculated and presented in Table B.1.

TABLe B.1. Priority number of technology fields.

\begin{tabular}{lll}
\hline \hline Row & Technology field & Priority number \\
\hline 1 & Biotechnology & 0.14 \\
2 & Advanced materials and polymer and chemical products & 0.10 \\
3 & Power and electronic hardware, laser and photonics & 0.18 \\
4 & ICT \& computer software & 0.19 \\
5 & Advanced machinery and equipment & 0.08 \\
6 & Advanced drugs & 0.14 \\
7 & Medical instrument, appliances, and equipment & 0.06 \\
8 & Advanced products in other fields & 0.11 \\
\hline
\end{tabular}

\section{Appendix C.}

The problem parameters are presented in Table C.1.

TABle C.1. Parameters.

\begin{tabular}{llllll}
\hline \hline Parameter & Value & Unit & Parameter & Value & Unit \\
\hline$T$ & 12 & Number & $r_{f}$ & $0.04 \& 0.11$ & $\%$ \\
$J$ & 8 & Number & $A$ & 0.7 & $\%$ \\
$G$ & $10-30$ & Number & $P_{j t}$ & $0.06-0.24$ & $\%$ \\
$S$ & $20-200$ & Number & $P_{\min }$ & 0.09 & $\%$ \\
$F$ & 2 & Number & $\mathrm{ROI}_{j g}$ & $0.11-0.37$ & $\%$ \\
$\mathrm{TRL}_{\text {min }}$ & 1 & Number & $\mathrm{ROI}_{\min }^{f}$ & $0.1 \& 0.17$ & $\%$ \\
$t_{m o}^{f}$ & 2 & Number & $\mathrm{Risk}_{j g}$ & $0.01-1$ & $\%$ \\
$t_{r e}^{f}$ & 2 & Number & $\mathrm{TLF}_{j g}$ & $0.1-1$ & $\%$ \\
$K$ & 3 & Number & $\mathrm{Camax}_{s}$ & $170-200$ & $\mathrm{M} \$$ \\
$n$ & 3 & Number & $\mathrm{Camin}_{s}$ & 100 & $\mathrm{M} \$$ \\
$\mathrm{TRL}_{j g t}$ & $1-9$ & Number & $D_{j g}$ & $1.6-20$ & $\mathrm{M} \$$ \\
TRLb $_{f}$ & $3 \& 5$ & Number & $\mathrm{Maa}_{j g}$ & $0.6-5$ & $10 \mathrm{M} \$$ \\
TRLe $_{f}$ & $5 \& 8$ & Number & & & \\
\hline
\end{tabular}

\section{APPENDIX D.}

Three sets of interdependent projects and three sets of inconsistent projects have been shown in Table D.1.

TABLE D.1. Interdependent and inconsistent projects.

\begin{tabular}{lll}
\hline \hline & Technology fields & Technological projects \\
\hline \multirow{2}{*}{ Interdependent projects } & $\mathrm{T} 1$ & $\mathrm{P} 5$ and P3 \\
& $\mathrm{T} 2$ & $\mathrm{P} 16$ and P5 \\
& $\mathrm{T} 5$ & $\mathrm{P} 4$ and P7 \\
Inconsistent projects & $\mathrm{T} 1$ & $\mathrm{P} 15$ and P30 \\
& $\mathrm{T} 4$ & $\mathrm{P} 3$ and P18 \\
& $\mathrm{T} 6$ & $\mathrm{P} 1$ and P7 \\
\hline
\end{tabular}




\section{REFERENCES}

[1] M. Abbassi, M. Ashrafi and E.S. Tashnizi, Selecting balanced portfolios of R\&D projects with interdependencies: a cross-entropy based methodology. Technovation 34 (2014) 54-63.

[2] D.C. Alvarado, S. Acha, N. Shah and C.N. Markides, A Technology Selection and Operation (TSO) optimisation model for distributed energy systems: mathematical formulation and case study. Appl. Energy 180 (2016) 491-503.

[3] S. Ardabili, Technology portfolio modeling in hybrid environment. Afr. J. Bus. Manage. 5 (2011) 4051-4058.

[4] N.M. Arratia, I.F. Lopez, S.E. Schaeffer and L. Cruz-Reyes, Static R\&D project portfolio selection in public organizations. Decis. Support Syst. 84 (2016) 53-63.

[5] H. Davoudpour, S. Rezaee and M. Ashrafi, Developing a framework for renewable technology portfolio selection: a case study at a R\&D center. Renew. Sustainable Energy Rev. 16 (2012) 4291-4297.

[6] M.P. de Matos, L.M. de Melo and M. Kahn, editors, Financing Innovation. Routledge, London (2014).

[7] M.W. Dickinson, A.C. Thornton and S. Graves, Technology portfolio management: optimizing interdependent projects over multiple time periods. IEEE Trans. Eng. Manage. 48 (2001) 518-527.

[8] A. Emelogu, S. Chowdhury, M. Marufuzzaman, L. Bian and B. Eksioglu, An enhanced sample average approximation method for stochastic optimization. Int. J. Prod. Econ. 182 (2016) 230-252.

[9] S.S. Ghazinoori and S.S. Ghazinoori, An Introduction to Science, Technology and Innovation Policy Making, 2nd edition. Tarbiat Modares University (In Persian), Tehran (2014).

[10] H. Gupta and M.K. Barua, Identifying enablers of technological innovation for Indian MSMEs using best-worst multi criteria decision making method. Technol. Forecasting Soc. Change 107 (2016) 69-79.

[11] H. Gupta and M.K. Barua, Supplier selection among SMEs on the basis of their green innovation ability using BWM and fuzzy TOPSIS. J. Cleaner Prod. 152 (2017) 242-258.

[12] G. Gurkan, A.Y. Ozge and T.M. Robinson, Sample-path optimization in simulation. In: Proceedings of Winter Simulation Conference. IEEE, Lake Buena Vista, FL (1994) 247-254.

[13] F. Hassanzadeh, H. Nemati and M. Sun, Robust optimization for interactive multiobjective programming with imprecise information applied to R\&D project portfolio selection. Eur. J. Oper. Res. 238 (2014) 41-53.

[14] T. Homem-De-Mello, Variable-sample methods for stochastic optimization. ACM Trans. Model. Comput. Simul. (TOMACS) 13 (2003) 108-133.

[15] C.Y. Huang, C.C. Chiou, T.H. Wu and S.C. Yang, An integrated DEA-MODM methodology for portfolio optimization. Oper. Res. 15 (2015) 115-136.

[16] M. Jafarzadeh, H.R. Tareghian, F. Rahbarnia and R. Ghanbari, Optimal selection of project portfolios using reinvestment strategy within a flexible time horizon. Eur. J. Oper. Res. 243 (2015) 658-664.

[17] A. Jahani, P. Mohammadi and H. Mashreghi, Effect of risk on evaluating the financing methods of new technology-based firms. Int. J. Ind. Eng. Prod. Res. 29 (2018) 133-146.

[18] E. Karasakal and P. Aker, A multicriteria sorting approach based on data envelopment analysis for R\&D project selection problem. Omega 73 (2017) 79-92.

[19] O. Kocadağlı and R. Keskin, A novel portfolio selection model based on fuzzy goal programming with different importance and priorities. Expert Syst. App. 42 (2015) 6898-6912.

[20] F. Kucukbay and C. Araz, Portfolio selection problem: a comparison of fuzzy goal programming and linear physical programming. Int. J. Optim. Control: Theor. App. (IJOCTA) 6 (2016) 121-128.

[21] C. Li, F. Liu, X. Tan and Y. Du, A methodology for selecting a green technology portfolio based on synergy. Int. J. Prod. Res. 48 (2010) 7289-7302.

[22] B. Li, Y. Zhu, Y. Sun, G. Aw and K.L. Teo, Multi-period portfolio selection problem under uncertain environment with bankruptcy constraint. Appl. Math. Model. 56 (2018) 539-550.

[23] I.S. Litvinchev, F. López, A. Alvarez and E. Fernández, Large-scale public R\&D portfolio selection by maximizing a biobjective impact measure. IEEE Trans. Syst. Man Cybern. Part A: Syst. Humans 40 (2010) 572-582.

[24] J.C. Mankins, Technology readiness and risk assessments: a new approach. Acta Astron. 65 (2009) $1208-1215$.

[25] H. Markowitz, Portfolio selection. J. Finance 7 (1952) 77-91.

[26] K. Marti, Y. Ermoliev, M. Makowski and G. Pflug, editors. Coping with Uncertainty: Modeling and Policy Issues. Springer Science \& Business Media 581 (2006).

[27] Z. Mashayekhi and H. Omrani, An integrated multi-objective Markowitz-DEA cross-efficiency model with fuzzy returns for portfolio selection problem. Appl. Soft Comput. 38 (2016) 1-9.

[28] V. Mohagheghi, S.M. Mousavi, B. Vahdani and M.R. Shahriari, R\&D project evaluation and project portfolio selection by a new interval type-2 fuzzy optimization approach. Neural Comput. App. 28 (2017) 3869-3888.

[29] N. Mohebbi and A.A. Najafi, Credibilistic multi-period portfolio optimization based on scenario tree. Phys. A: Stat. Mech. App. 492 (2018) 1302-1316.

[30] N. Mokhtarzadeh, S.S. Ahangari and M. Faghei, Proposing a three dimensional model for selecting a portfolio of R\&D projects. IAMOT 2016 Conference Proceedings, Orlando, FL (2016).

[31] A. Namazian and S.H. Yakhchali, Modeling and solving project portfolio and contractor selection problem based on project scheduling under uncertainty. Proc.-Soc. Behav. Sci. 226 (2016) 35-42.

[32] M.E. Raynor and X. Leroux, Strategic flexibility in R\&D. Res.-Technol. Manage. 47 (2004) 27-32.

[33] J. Rezaei, Best-worst multi-criteria decision-making method. Omega 53 (2015) 49-57. 
[34] J. Rezaei, J. Wang and L. Tavasszy, Linking supplier development to supplier segmentation using Best Worst Method. Expert Syst. App. 42 (2015) 9152-9164.

[35] J. Rezaei, T. Nispeling, J. Sarkis and L. Tavasszy, A supplier selection life cycle approach integrating traditional and environmental criteria using the best worst method. J. Cleaner Prod. 135 (2016) 577-588.

[36] R.Y. Rubinstein and A. Shapiro, Optimization of static simulation models by the score function method. Math. Comput. Simul. 32 (1990) 373-392.

[37] R.Y. Rubinstein and A. Shapiro, Discrete Event Systems: Sensitivity Analysis and Stochastic Optimization by the Score Function Method. John Wiley \& Sons Inc, New York, NY (1993).

[38] N. Salimi, Quality assessment of scientific outputs using the BWM. Scientometrics 112 (2017) 195-213.

[39] N. Salimi and J. Rezaei, Measuring efficiency of university-industry Ph.D. projects using best worst method. Scientometrics 109 (2016) 1911-1938.

[40] N. Salimi and J. Rezaei, Evaluating firms' R\&D performance using best worst method. Eval. Prog. Plan. 66 (2018) $147-155$.

[41] T.L. Satty, The Analytic Hierarchy Process. McGraw-Hill International, New York, NY (1980).

[42] M. Shariatmadari, N. Nahavandi, S.H. Zegordi and M.H. Sobhiyah, Integrated resource management for simultaneous project selection and scheduling. Comput. Ind. Eng. 109 (2017) 39-47.

[43] M. Tavana, K. Khalili-Damghani and S. Sadi-Nezhad, A fuzzy group data envelopment analysis model for high-technology project selection: a case study at NASA. Comput. Ind. Eng. 66 (2013) 10-23.

[44] M. Tavana, M. Keramatpour, F.J. Santos-Arteaga and E. Ghorbaniane, A fuzzy hybrid project portfolio selection method using data envelopment analysis, TOPSIS and integer programming. Expert Syst. App. 42 (2015) 8432-8444.

[45] R.J. Terrile, B.L. Jackson and A.P. Belz, Consideration of risk and reward in balancing technology portfolios. In: 2014 IEEE Aerospace Conference. IEEE, Big Sky, MT (2014) 1-8.

[46] S.A. Torabi, R. Giahi and N. Sahebjamnia, An enhanced risk assessment framework for business continuity management systems. Safety Sci. 89 (2016) 201-218.

[47] M. Velasquez and P.T. Hester, An analysis of multi-criteria decision making methods. Int. J. Oper. Res. 10 (2013) 56-66.

[48] J. Wonglimpiyarat, Entrepreneurial financing for venture and innovation development. Int. J. Foresight Innov. Policy 5 (2009) $234-243$.

[49] J. Wonglimpiyarat, Government programmes in financing innovations: comparative innovation system cases of Malaysia and Thailand. Technol. Soc. 33 (2011) 156-164.

[50] J. Wonglimpiyarat, Technology Financing and Commercialization: Exploring the Challenges and How Nations Can Build Innovative Capacity. Palgrave Macmillan UK, London (2014).

[51] Y. Wu, C. Xu, Y. Ke, K. Chen and X. Sun, An intuitionistic fuzzy multi-criteria framework for large-scale rooftop PV project portfolio selection: case study in Zhejiang, China. Energy 143 (2018) 295-309.

[52] O. Yu, Technology Portfolio Planning and Management: Practical Concepts and Tools. In Vol. 96 of International Series in Operations Research 83 Management Science Springer, New York, NY (2007). 